\title{
Energy metabolism in glioblastoma stem cells: PPARa a metabolic adaptor to intratumoral microenvironment
}

\author{
Alessia Fidoamore ${ }^{1, *}$, Loredana Cristiano, ${ }^{1, *}$, Chiara Laezza ${ }^{2}$, Renato Galzio ${ }^{1}$, \\ Elisabetta Benedetti ${ }^{1}$, Benedetta Cinque ${ }^{1}$, Andrea Antonosante ${ }^{1}$, Michele d'Angelo ${ }^{1}$, \\ Vanessa Castelli ${ }^{1}$, Maria Grazia Cifone ${ }^{1}$, Rodolfo Ippoliti ${ }^{1}$, Antonio Giordano ${ }^{3,5}$ and \\ Annamaria Cimini ${ }^{1,3,4}$ \\ ${ }^{1}$ Department of Life, Health and Environmental Sciences, University of L'Aquila, L'Aquila, Italy \\ 2 Institute of Endocrinology and Experimental Oncology, IEOS, CNR, Naples, Italy \\ ${ }^{3}$ Sbarro Institute for Cancer Research and Molecular Medicine, Department of Biology, Temple University, Philadelphia, \\ Pennsylvania, USA \\ ${ }^{4}$ National Institute for Nuclear Physics (INFN), Gran Sasso National Laboratory (LNGS), Assergi, Italy \\ ${ }^{5}$ Department of Medicine, Surgery and Neuroscience, University of Siena, Siena, Italy \\ * These authors have equally contributed to the paper \\ Correspondence to: Annamaria Cimini, email: annamaria.cimini@univaq.it \\ Keywords: tumor stem cells, metabolism, PPARs \\ Received: September 18,2016 Accepted: June 10,2017 Published: July 07, 2017
}

Copyright: Fidoamore et al. This is an open-access article distributed under the terms of the Creative Commons Attribution License 3.0 (CC BY 3.0), which permits unrestricted use, distribution, and reproduction in any medium, provided the original author and source are credited.

\section{ABSTRACT}

Glioblastoma (GB), the most-common cancer in the adult brain, despite surgery and radio/ chemotherapy, is to date almost incurable. Many hypoxic tumors, including GB, show metabolic reprogramming to sustain uncontrolled proliferation, hypoxic conditions and angiogenesis. Peroxisome Proliferator-activated Receptors (PPAR), particularly the $a$ isotype, have been involved in the control of energetic metabolism. Herein, we characterized patient-derived GB neurospheres focusing on their energetic metabolism and PPARa expression. Moreover, we used a specific PPARa antagonist and studied its effects on the energetic metabolism and cell proliferation/survival of GB stem cells. The results obtained demonstrate that tumor neurospheres are metabolically reprogrammed up-regulating glucose transporter, glucose uptake and glycogen and lipid storage, mainly under hypoxic culture conditions. Treatment with the PPARa antagonist GW6471 resulted in decreased cell proliferation and neurospheres formation. Therefore, PPARa antagonism arises as a potent new strategy as adjuvant to gold standard therapies for GB for counteracting recurrences and opening the way for pre-clinical trials for this class of compounds. When tumor neurospheres were grown in hypoxic conditions in the presence of different glucose concentrations, the most diluted one $(0.25 \mathrm{~g} / \mathrm{L})$ mimicking the real concentration present in the neurosphere core, PPARa increase/PPARy decrease, increased proliferation and cholesterol content, decreased glycogen particles and LDs were observed. All these responses were reverted by the $72 \mathrm{~h}$ treatment with the PPARa antagonist.

\section{INTRODUCTION}

Glioblastoma (GB) is the most common primary brain tumor with poor prognosis. Its invasive nature and its resistance to therapy result in a very high rates of recurrence [1]. GB stem cells (GSCs) have been indicated as responsible for drug resistance and relapse. GSCs reside in intratumoral perivascular and necrotic/ hypoxic niches [2]. Hypoxia has recently emerged as a major factor influencing tumor proliferation and malignant progression. Although some of the effects of hypoxia negatively impact tumor cell growth, they 
may, antithetically, lead to hypoxia-driven responses that enhance malignant progression and aggressiveness, ultimately resulting in increased resistance to therapy and poor long-term prognosis. In GB, the malignant progression associated with tumor hypoxia appears to be mediated by several mechanisms, including changes in gene expression, inactivation of suppressor genes or activation of oncogenes, genomic instability, loss of apoptotic potential, induction of angiogenesis and invasive phenotypical changes [3-4]. Cellular responses to hypoxia are commonly regulated by the HIFs, a family of transcriptional factors upregulating the transcription of numerous hypoxia-inducible genes. HIF proteins function as master regulators of oxygen levels in cells through conformational changes in response to varying $\mathrm{O}_{2}$ concentrations, and, in gliomagenesis, as key regulatory elements in a variety of physiological and pathological responses to hypoxia, regulating genes involved in tumor progression, angiogenesis, drug resistance and GSC phenotype maintenance [5]. HIF-1 $\alpha$ induces the expression of genes that trigger the tumor metabolic shift, promoting the increase of glucose uptake, the expression of glycolytic enzymes, the anaerobic glycolytic pathway of ATP generation,, and lactate production; it regulates pyruvate metabolism in both hypoxic and normoxic cells, increasing the production of precursors needed for cell growth $[3,6]$. HIF-1 $\alpha$ also controls fatty acid and glycogen synthesis, inducing the expression of the enzymes required to convert glucose to glycogen, including hexokinase (HK1 or HK2), phosphoglucomutase1 (PGM1), UDPglucose pyrophosphorylase (UGP2), glycogen synthase (GYS1), glycogen branching enzyme (GBE1), as well as the gene encoding PPP1R3C, which activates GYS1 and inhibits liver-type glycogen phosphorylase (PYGL), that breaks down glycogen [7]

Although little is known about the bioenergetics resetting of CSCs, it would appear that a direct link exists between the occurrence of a metabolic switch from OXPHOS to aerobic glycolysis and the occurrence and maintenance of CSC cellular states [8]. A direct link between glucose metabolism and cancer stem/initiating cells has similarly been established in GB cancer tissues [9]. It has been suggested that certain bioenergetic features such as the Warburg effect can no longer be viewed as the single metabolic entity shared by all the cancer tissues, but rather as the archetypical aspect of the undifferentiated state, owned by CSCs [8]. Thus, the permanent shift toward a Warburg effect might be an essential contributory cause to cancer and might represent the central link between the genetic/epigenetic instability and the CSC theory, considering that a characteristic and essential feature of each neoplasm is the lack of differentiation [10].

Analyzing the general lipid composition of human gliomas, it was shown that total lipids accounted for $15-35 \%$ of the dry weight of the tissue with about $25 \%$ cholesterol not found in its free form while, in normal brain tissue, all cholesterol was in its free form [11]. The free fatty acid level, including polyunsaturated fatty acids, particularly linoleic acid, was higher in glioma, meningioma, neurinoma and carcinoma than normal brain tissue, suggesting that gliomas developed an altered metabolism for fatty acids. Another important biosynthetic process within lipid metabolism, up-regulated in GB, is the mevalonate pathway, which is known to facilitate the synthesis of cholesterol. Cholesterol esters, formed by the esterification of cholesterol with long-chain fatty acids, have been shown to be present only in high-grade gliomas [12-13]. However, why neoplastic tissues form and accumulate cholesterol esters, and how tumor cells utilize this class of lipids is unknown. Given that the levels of free cholesterol are strictly regulated by negative feedback mechanisms, formation of cholesterol esters could be the strategy that glioma cells use to store cholesterol. When cells require cholesterol, cholesterol esters could quickly release cholesterol for cell growth or survival. Therefore, considering that cholesterol esters are absent in healthy brain tissues, preventing their utilization may constitute a possible therapeutic strategy to inhibit malignant glioma growth [14]. Although it is generally accepted that tumor cells, particularly CSC, modify their glucose and lipid metabolism inside tumor microenvironment, the specific metabolic pathways and their regulation are still poorly understood. Owing to their crucial roles in energetic metabolism, many Authors have considered the role of the peroxisome proliferator-activated receptors (PPARs) in tumorigenesis, with some studies implicating these factors in the promotion and development of cancer, while others presenting evidence for an antitumorigenic role for these receptors [15]. In brain tumors PPARs have been demonstrated to play a role in controlling growth and malignancy [16-22] as well as growth and expansion of brain GSC [23]. PPAR $\alpha$ activation increases proliferation in breast cancer cell lines and in renal cell carcinoma cell line [24-25] and causes liver cancer in rodents, while PPAR $\alpha$ null-mice are shown to be resistant to hepatocarcinogenic effects of PPAR $\alpha$ agonists [26]. Despite these findings, its function as tumor suppressor or inducer in cancers is still uncertain and may be related to cancer/cell type and/or specific microenvironment of the tumor.

On the basis of the reported findings, this work was focused on the possible correlation between the peculiar energetic metabolism of GSCs and PPARs. In particular, we evaluated the expression of PPAR $\alpha$ and $\gamma$ and the levels of proteins implicated in glucose and lipid metabolism in GSC, obtained from bioptic GB specimens and grown in normoxia and hypoxia, focusing the attention on some proteins crucial for glycolytic and cholesterol pathways and for glycogen and lipid storage.

Our results allow to positivly correlate $\operatorname{PPAR} \alpha$ to proliferation, survival and resistance of GSCs, through its regulation of glucose and lipid metabolism and 
demonstrate that a specific synthetic antagonist of PPAR $\alpha$, GW6471, inhibits these effects. The specific synthetic PPAR $\alpha$ antagonist, GW6471 favours and reinforces the binding of co-repressors to the transcription factor [27], thus inhibiting its activity. The study of the effect of this antagonist on GSCs allows to elucidate the role of PPAR $\alpha$ in their metabolism and to propose this molecule as potential drug specifically targeting these cells.

\section{RESULTS}

\section{GSCs characterization}

GSCs were characterized by the expression of stemness markers (Figure 1), such as SOX2 (A), nestin (B), CD133 (C), GFAP (D) by immunofluorescence and cytofluorimetric assay. Moreover, the malignancy marker $\beta$-tubulinIII (E) was also assessed. The results obtained, in agreement with the current literature, demonstrate that our cells were GSCs.

\section{Expression of PPAR $\alpha$ and $\gamma$ in GSCs}

The cell proliferation assay (Figure 2A) showed that hypoxia significantly enhances GSCs proliferation. Moreover, the hypoxic cells exhibited higher levels of HIF-1 $\alpha$ protein (Figure 2B), most probably active, being mainly localized to the nucleus (Figure 2C). PPAR $\alpha$ and $\gamma$ expression was evaluated by western blotting analysis and immunofluorescence (Figures $2 \mathrm{~B}$ and $2 \mathrm{C}$ ). PPAR $\alpha$, showed a cytoplasmic and nuclear localization and was significantly upregulated in hypoxic cells, while PPAR $\gamma$ was localized mainly in the cytoplasm and in hypoxia it appears at lower levels.

\section{Hypoxia promotes accumulation of glycogen and LDs}

The hypoxic challenge increased glycogen as shown by specific immunofluorescence (Figure 3A). FACS analysis (Figure 3B) showed that glycogen-positive cells were more numerous in hypoxia than in normoxia. In parallel, a decrease, at protein level, of the active form of GSK $3 \beta$, responsible for the repression of the glycogen synthase and the increase of its inactive phosphorylated form (Figure 3C) was observed, thus indicating increase of glycogen synthesis in hypoxia. In addition, the expression of the glucose transporter, GLUT-3, specifically present in brain tumor initiating cells, [9] was examined. The western blotting and immunofluorescence results (Figures 3C and 3D) showed that GLUT-3, mainly localized in the core of the normoxic neurospheres, appeared upregulated and ubiquitously distributed in hypoxic spheres.
LD accumulation was observed in adult neural stem cells [28], in colorectal cancer stem cells [29], in glioma cells, where they have been correlated to the malignancy grade [30, 31]. LDs, detected by BODIPY 493/503 (Figure $3 \mathrm{E}$ ), were mainly localized in the core of both normoxic and hypoxic neurospheres and strongly increased in hypoxic condition. In parallel, perilipin, a LD membrane protein, crucial for the regulation of lipids storage/ mobilization [32] increased significantly in hypoxia, while adipophilin, other component of LD membrane, was not significantly affected (Figure 3F).

\section{Effect of PPAR $\alpha$ antagonist GW6471 on normoxic and hypoxic GSCs}

A specific synthetic PPAR $\alpha$ antagonist, GW6471, that favours and reinforces the binding of co-repressors to the transcription factor [27], inhibiting its activity, highly specific by the binding the peroxisome proliferatoractivated receptor- $x$ ligand-binding domain bound, was then used. The dose-effect curve $(2-16 \mu \mathrm{M})$, (Figure 4A), demonstrated that the antagonist determined, after $72 \mathrm{hr}$, a progressive dose-dependent reduction of cell proliferation both in normoxic and hypoxic conditions. In normoxia the effect was significant already at $4 \mu \mathrm{M}$, in hypoxia the drug affected cell proliferation, although to a lesser extent, starting from $8 \mu \mathrm{M}$ dose and significantly at $16 \mu \mathrm{M}$. It is worth noting that this compound has been already tested on human normal renal epithelial cells at $25 \mu \mathrm{M}$, where it did not cause any toxicity. [25].

In addition to its cytostatic effect, GW6471 promoted apoptosis (Figure 4B). The increase of cell death was dose-dependent in both conditions, although hypoxic cells were more resistant to the treatment. The analysis of cell morphology, by phase contrast microscopy (Figure 4C) showed that GW6471 induced a disaggregation of normoxic spheres, while the hypoxic ones, although reduced in size, resulted still compact also at higher doses,. The effect of the antagonist was evaluated also on the formation of neurospheres, performing the $72 \mathrm{hr}$ treatment on single dissociated stem cells. The phase contrast images of neurospheres (Figure 4D) and the analysis of the relative counts (Figure 4E) revealed that GW6471 inhibited the formation of the spheres at the different doses both in normoxia and hypoxia. In fact, $8 \mu \mathrm{M}$ in normoxia decreased the number of spheres to about $50 \%$, while in hypoxia the same effect was observed only at $16 \mu \mathrm{M}$, in agreement with the BrdU results. After $72 \mathrm{hr}$ of treatment, normoxic and hypoxic spheres were monitored for further 7 days in vitro and analysed by phase contrast microscopy (Figure 4F). In both conditions, neurospheres derived from the residual and resistant cells to the treatment, were smaller in size than their controls, suggesting that the cells that did not undergo apoptosis during the treatment, were however subjected to an arrest/reduction of cell proliferation. 
A

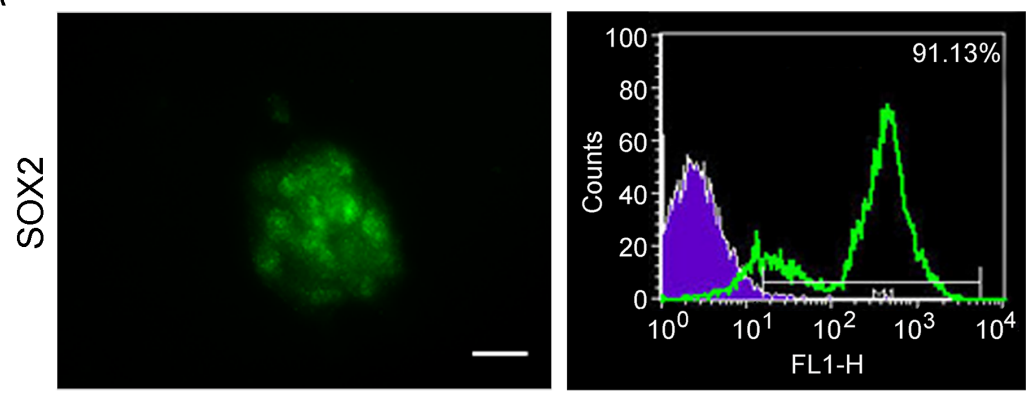

B

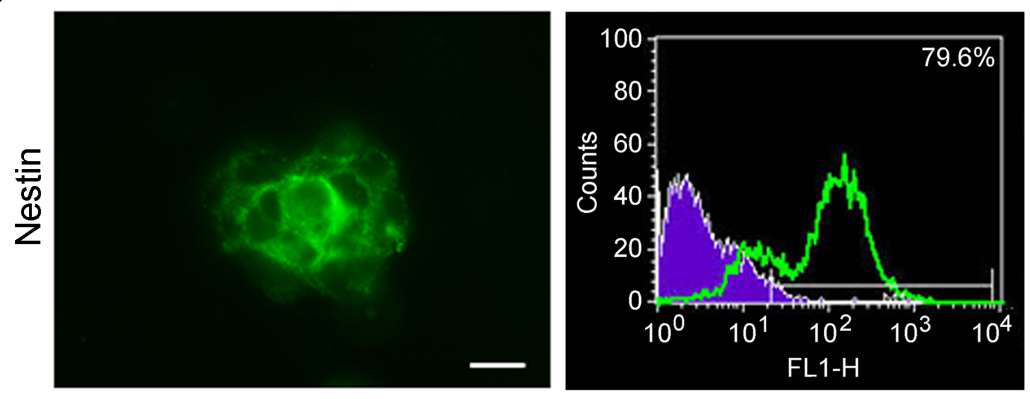

C

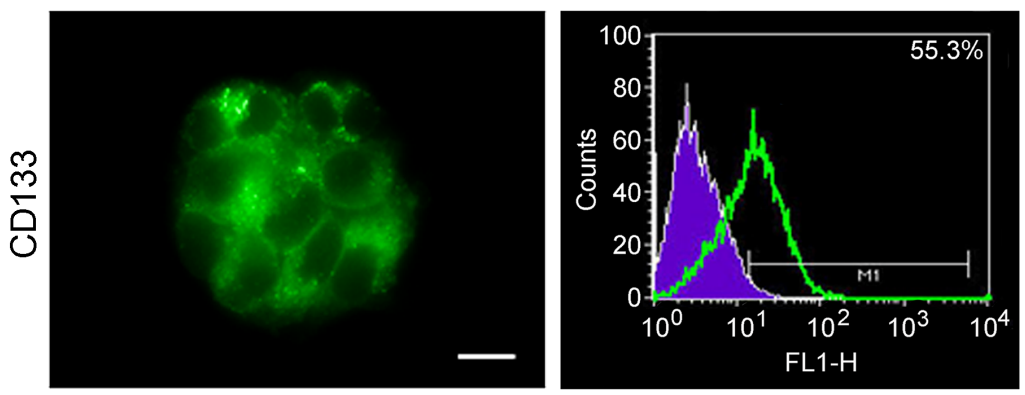

$\mathrm{D}$

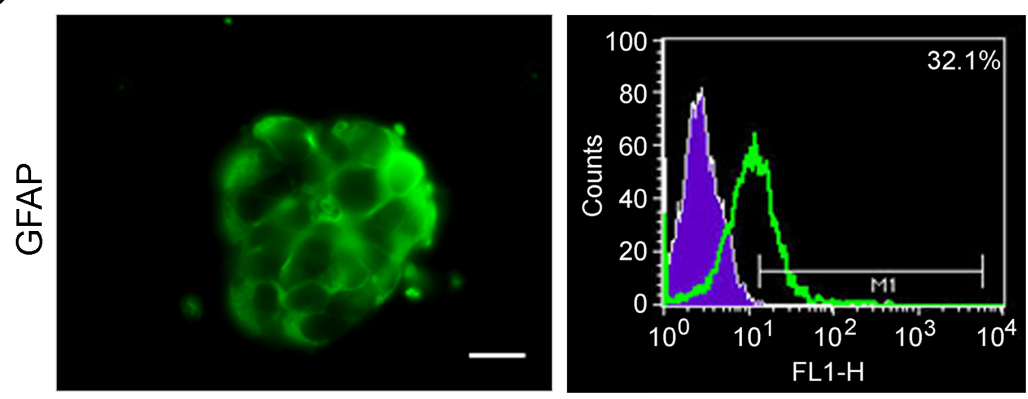

$\mathrm{E}$
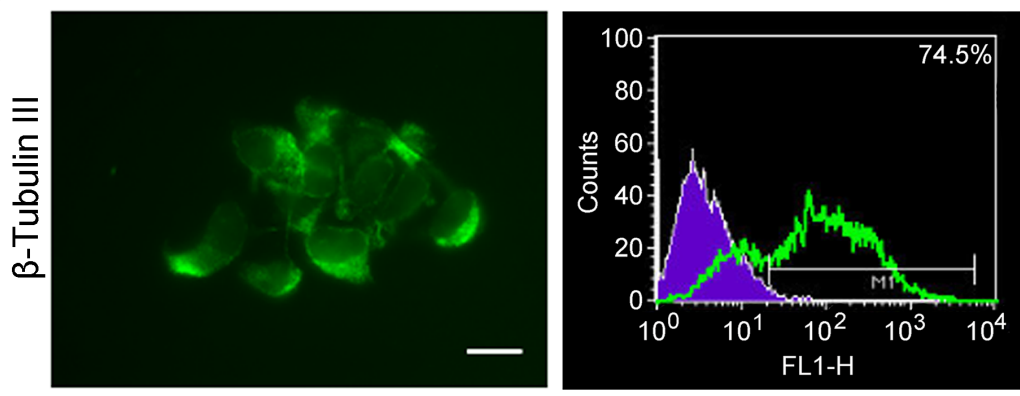

Figure 1: Stemness markers and multipotency of GSCs. GSCs were characterized by cytofluorimetry and immunofluorescence. A.-E. Neurosphers characterization for stemness markers such as SOX2, Nestin, CD133, GFAP and $\beta$-tubulin III, show that GScs express all the stemness markers as well as the malignancy marker $\beta$-tubulin III. Bar $=25 \mu \mathrm{m}$. 

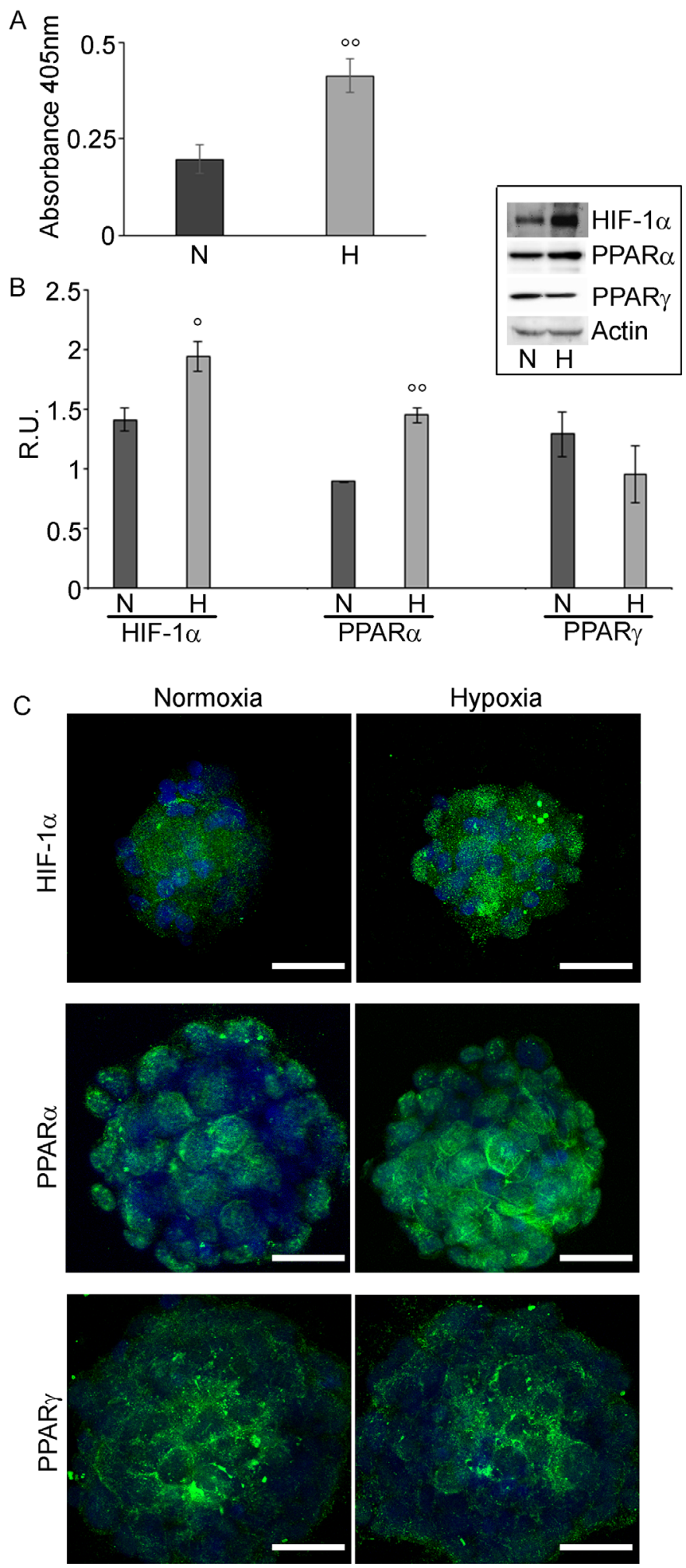

Figure 2: GSCs Proliferation assay and HIF-1 $\alpha$ and PPAR $\alpha$ and $\gamma$ expression in GSCs. A. BrdU assay in normoxia (N) and in hypoxia $(\mathrm{H})$ of GSCs shows that hypoxic cells are more proliferating than normoxic ones.. Data are means \pm SD of 3 different experiments. ${ }^{\circ}, p<0.001$, hypoxia $v s$ normoxia. B. Western blotting analysis for HIF-1 $\alpha$, PPAR $\alpha$ and $\gamma$ in normoxic and hypoxic GSCs. In hypoxic conditions, a higher expression of HIF- $1 \alpha$ and PPAR $\alpha$ is observed, while PPAR $\gamma$ appears not significantly different. Data are means \pm SD of 3 different experiments. ${ }^{\circ}, p<0.01,{ }^{\circ}, p<0.001$, hypoxia $v s$ normoxia. C. Immunofluorescence for HIF-1 $\alpha$, PPAR $\alpha$ and $\gamma$ in normoxic and hypoxic GSCs. In agreement with the western blotting results, HIF-1 $\alpha$ and PPAR $\alpha$ appeared highly expressed, mainly at nuclear level. Nuclei are stained with Dapi. Bar $=25 \mu \mathrm{m}$. 
A

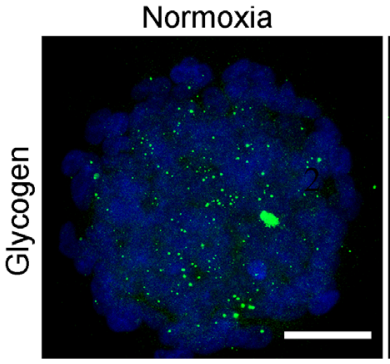

B

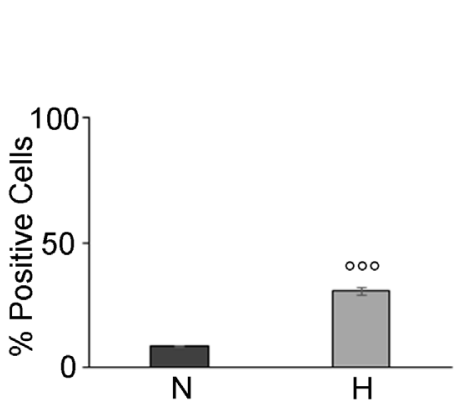

C
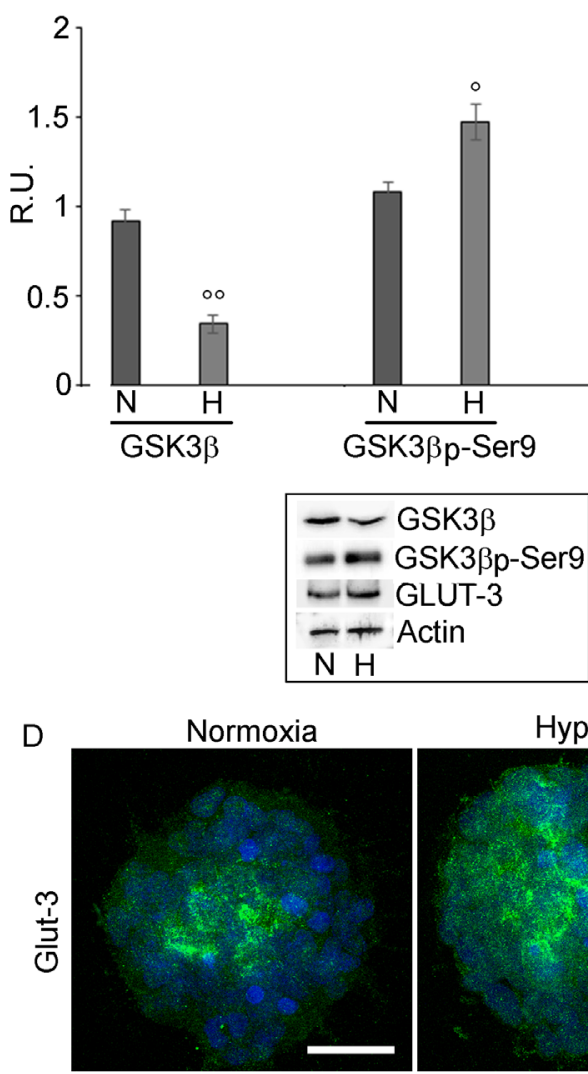

Hypoxia

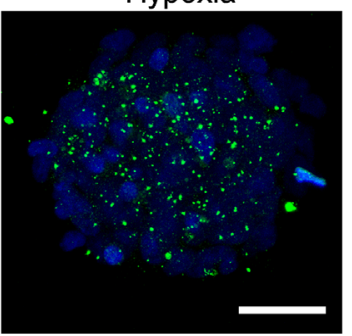

Normoxia
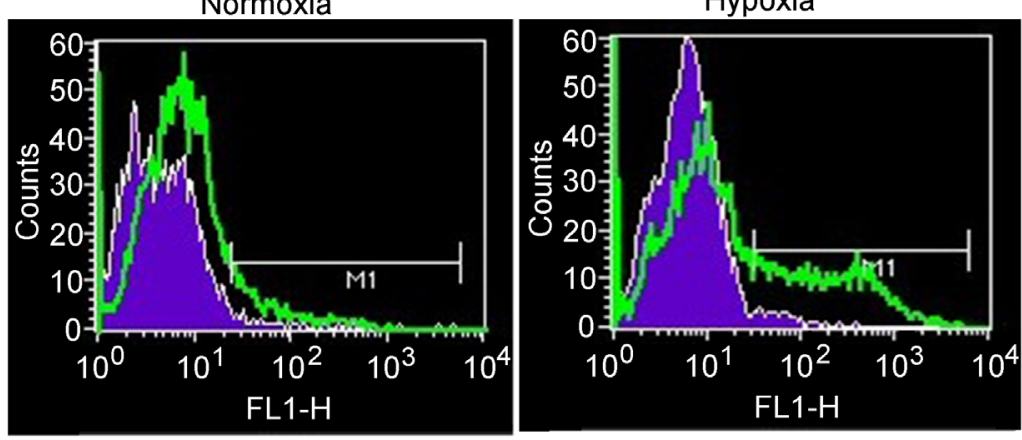

E
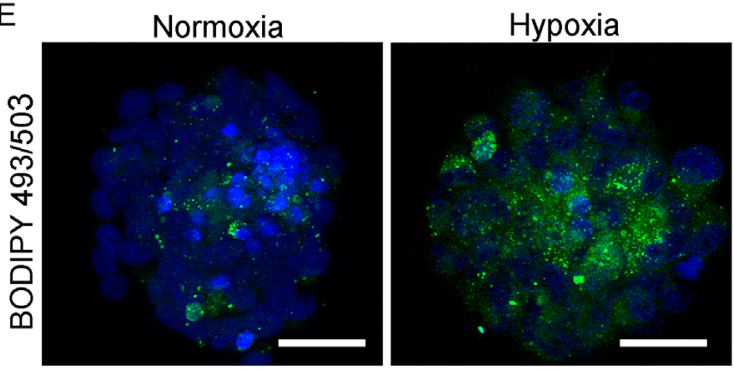

$\mathrm{F}$

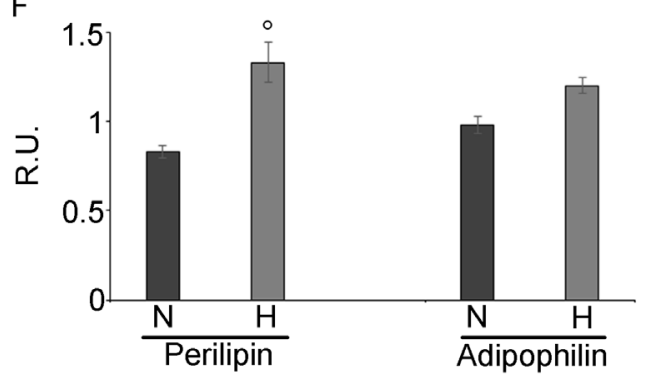

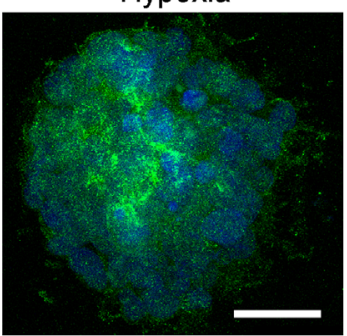

Figure 3: Glycogen and LD in GSCs evaluated by confocal microscopy and cytofluorimetry. A. glycogen localization in normoxic and hypoxic GSCs shows that glycogen is highly present in hypoxic conditions . Nuclei are stained with Dapi. Bar $=25 \mu \mathrm{m}$. $\mathbf{B}$. Glycogen evaluation by FACS analysis confirmed the higher presence of glycogen in hypoxic neurospheres. Data are means \pm SD of 3 different experiments. ${ }^{\circ 0}, p<0.0001$ hypoxia $v$ s normoxia. C. Western blotting analysis for GSK3 $\beta$, p-GSK3 $\beta$-ser9 and GLUT-3 shows a decrease of the active GSK $3 \beta$ paralleled by an increase of the inactive form p-GSK3 $\beta$-ser9. GLUT-3 increases in hypoxia. Data are means \pm SD of 3 different experiments. ${ }^{\circ}, p<0.01,{ }^{\circ}, p<0.001$ hypoxia $v s$ normoxia D. GLUT-3 immunofluorescence in normoxic and hypoxic GSCs confirmed the higher presence of GLUT-3 in hypoxic GSCs. Nuclei are stained with Dapi. Bar $=25 \mu \mathrm{m}$. E. BODIPY $493 / 503$ staining of LD in $\mathrm{N}$ and $\mathrm{H}$ conditions show the higher LD content in hypoxic neurospheres. Nuclei are stained with Dapi. Bar $=25 \mu \mathrm{m}$. F. Western blotting analysis for perilipin and adipophilin in normoxic and hypoxic GSCs shows that perilipin is significantly increased in hypoxia, while adipophilin is not significantly modulated. Data are means $\pm \mathrm{SD}$ of 3 different experiments. ${ }^{\circ}, p<0.01$ hypoxia $v s$ normoxia. 

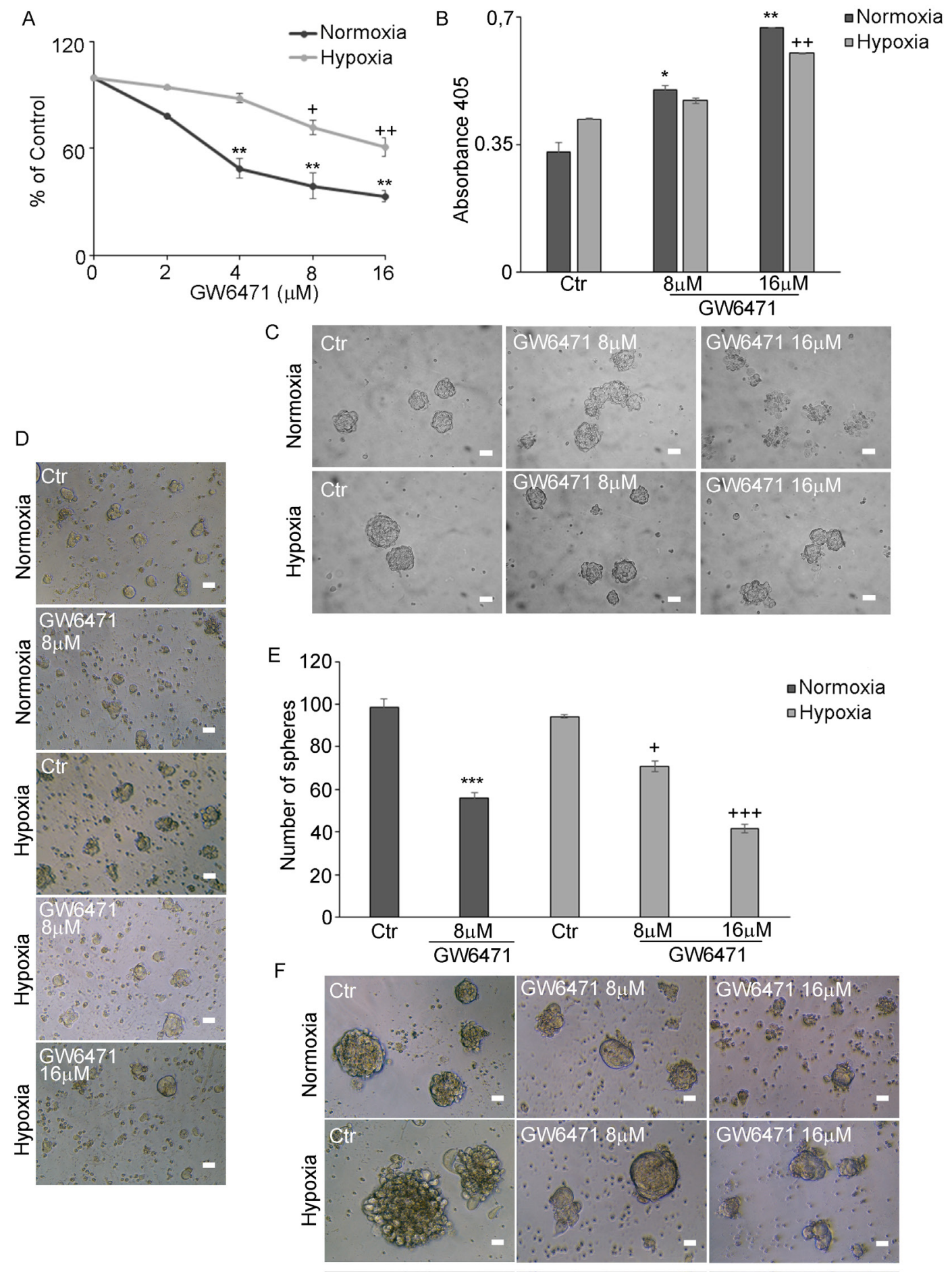

Figure 4: GW6471 effect on normoxic and hypoxic neurospheres. A. BrdU assay in $\mathrm{N}$ and $\mathrm{H}$ neurospheres treated with $2-16 \mu \mathrm{M}$ GW6471 shows that normoxic cells are significantly affected in the range 4-16 $\mu \mathrm{M}$, while the hypoxic cells appeared more resistant being decreased in the range 8-16 $\mu \mathrm{M}$. Data are means $\pm \mathrm{SD}$ of 3 different experiments.,$+ p<0.01 ;++, p<0.001$, hypoxia versus respective control; **, $p<0.001$, normoxia versus respective control. B. Apoptosis assay shows that in normoxic cells apoptosis increased at $8-16 \mu \mathrm{M}$ $\mathrm{GW}$, while in hypoxia only $16 \mu \mathrm{M}$ was effective in inducing cell death.. Data are means $\pm \mathrm{SD}$ of 3 different experiments.,$++ p<0.001$, hypoxia versus respective control; *, $p<0.01{ }^{* *}, p<0.001$, normoxia $v s$ the respective control. C. Phase contrast microscopy of control and treated neurospheres in hypoxic and normoxic conditions. Bar $=70 \mu \mathrm{m}$. D. Phase contrast microscopy of dissociated single cells from neurospheres after the treatment in hypoxia and normoxia. Bar $=70 \mu \mathrm{m}$. E. Number of spheres formed after the treatment of dissociated single cells. Data are means $\pm \mathrm{SD}$ of 3 different experiments. ***, $p<0.001$ normoxia with respect to the respective control condition; + , $p<0.01 ;+++, p<0.0001$, hypoxia $v s$ respective control condition. F. Phase contrast microscopy of neurospheres formed after antagonist treatment and monitored for further 7 days in vitro. Bar $=70 \mu \mathrm{m}$. 


\section{GW6471 treatment on glycogen and lipid content}

The levels of glycogen and lipid storage were investigated after antagonist treatment. Figure 5A shows that the inhibition of PPAR $\alpha$ in normoxia with $8 \mu \mathrm{M}$
GW6471 determined a strong reduction of glycogen content in all cells of the spheres, while in hypoxia it induced a slight decrease of glycogen granules limited to the external layers of the neurospheres, while the cells in the core preserved their storage. The $16 \mu \mathrm{M}$ dosage in
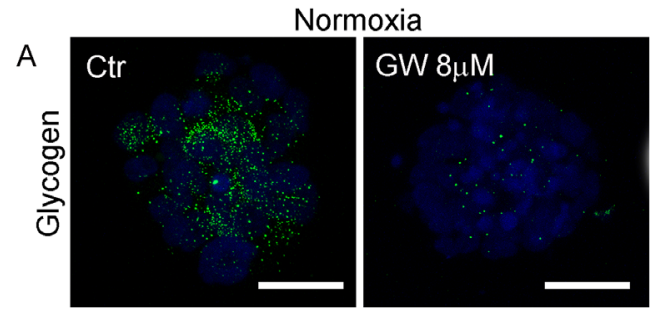

B

$$
2
$$
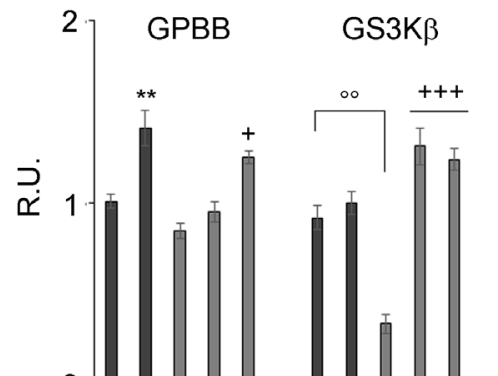

\begin{tabular}{rr}
$8 \mu \mathrm{M}$ & $-+\cdots+$ \\
$16 \mu \mathrm{M}$ & $-\ldots+$ \\
\hline
\end{tabular}

GW6471

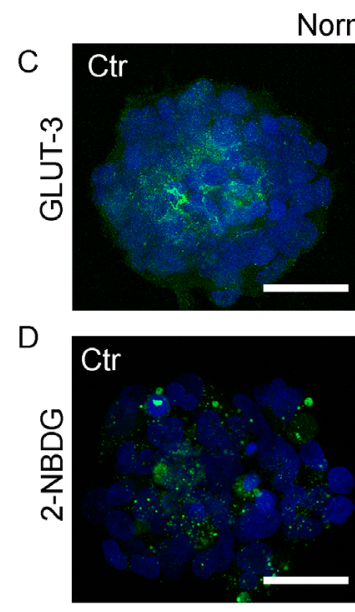

Normoxia
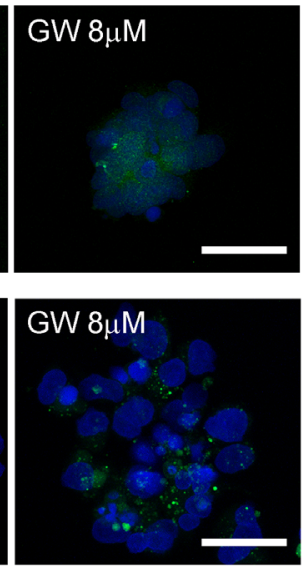

¿Normoxia

口Hypoxia
pGS3K $\beta$ Hexokinase

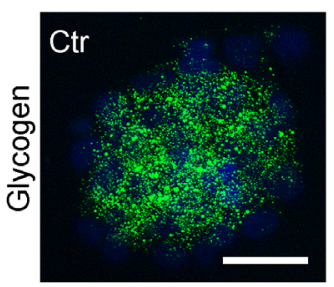

Hypoxia
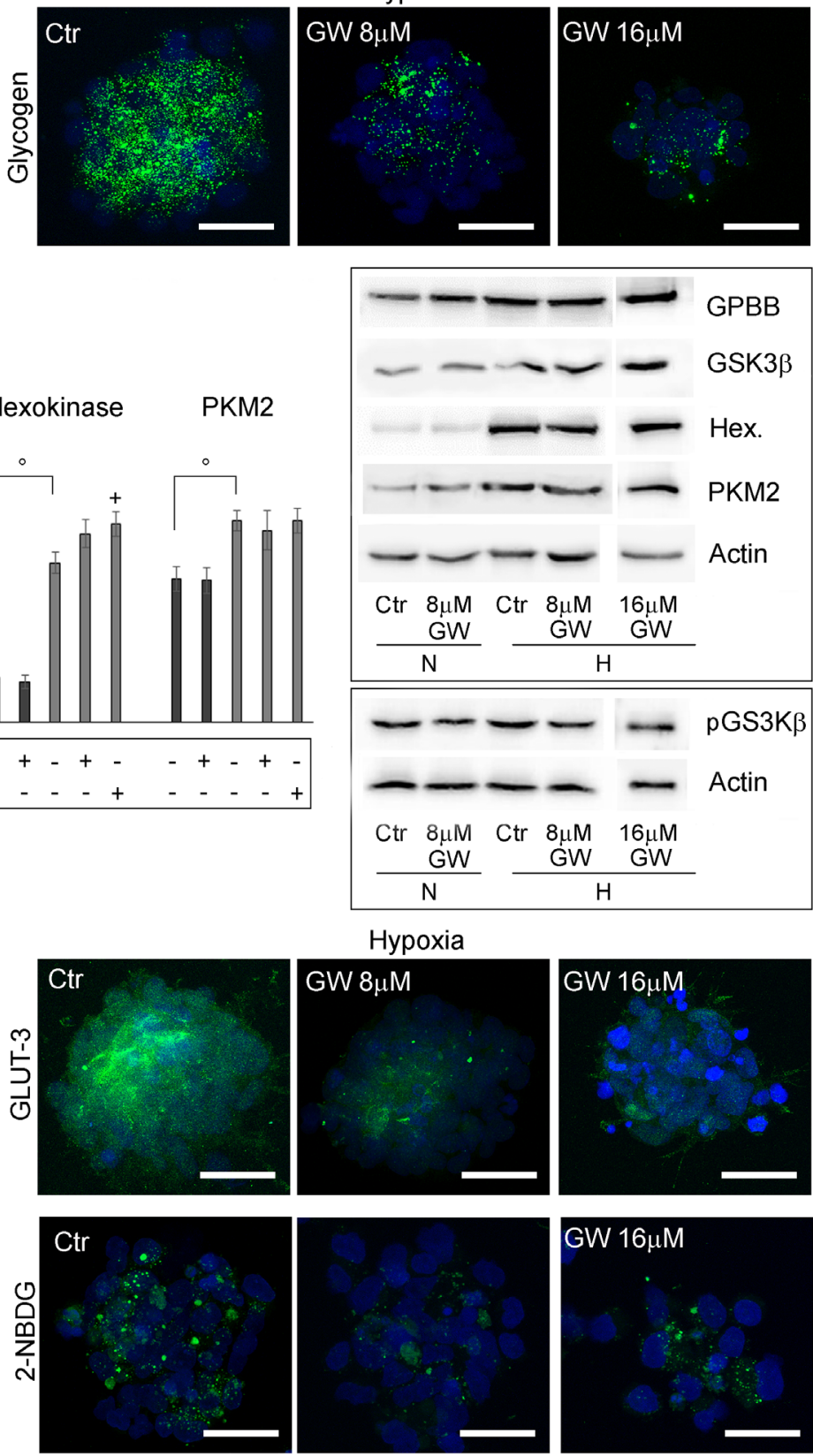

Figure 5: GW6471 effects on glycogen storage and metabolism of GSCs. A. Glycogen levels in treated GSCs by confocal microscopy shows that glycogen is highly present in hypoxic neurospheres and that GW6471 is able to decrease glycogen both in normoxic and hypoxic neurospheres. Nuclei are stained with Dapi. Bar $=25 \mu \mathrm{m}$. B. Western blotting analysis for GPBB, GSK3 $\beta$, p-GS3K $\beta$-ser9, Hexokinase and PKM2. Data are means \pm SD of 3 different experiments. $+, p<0.01,++, p<0.001,+++, p<0.0001$, hypoxia with respect to the respective control; ${ }^{\circ}, p<0.01,{ }^{\circ}, p<0.001$, hypoxia $v s$ normoxia. ${ }^{* *}, p<0.001$, normoxia $v s$ the respective control. C. GLUT-3 immunofluorescence in treated GSCs in normoxic and hypoxic conditions shows that GLUT-3 is increased in hypoxia and that the treatment decreases the transporter both in normoxia and hypoxia. Nuclei are stained with Dapi. Bar $=25 \mu \mathrm{m}$. D. Glucose uptake in treated GSCs by deoxy-glucose analog shows that the treatment was able to decrease glucose uptake. Nuclei are stained with Dapi Bar $=25 \mu \mathrm{m}$. 
hypoxia resulted more effective in reducing the glycogen content also in the hypoxic core of the spheres. The analysis, by western blotting, of key enzymes involved in glycogenolysis and in glycolytic pathways (Figure 5B) demonstrated that glycogen phosphorylase (GPBB), a brain specific isoenzyme of the first rate-limiting step of glycogenolysis, responsible for the conversion of glycogen into glucose 1-phosphate, was significantly increased in the normoxic cells, after treatment, in agreement with the decrease of glycogen granules observed by immunofluorescence. In hypoxia, no variation of the protein at $8 \mu \mathrm{M}$ antagonist was observed, while it significantly increased at $16 \mu \mathrm{M}$. It is worth noting, only in hypoxia, that the treatment with GW6471 both at 8 and $16 \mu \mathrm{M}$ promoted an increase of the expression of the active form of GSK3 $\beta$ as well as a reduction of its inactive phosphorylated form. It appears that, while in normoxia the reduction of glycogen content may be due mainly to an increase of glycogenolysis, in hypoxia it may be dependent on both the blockade of glycogen synthesis and on the increase of glycogen demolition. As regard glycolytic enzymes, hexokinase II and pyruvate kinase M2 (PKM2), highly present in proliferating tumor cells, they were significantly upregulated in hypoxia compared to normoxia, since they are HIF-1 $\alpha$ target genes [7]; the treatment with GW6471 did not affect their protein levels in both conditions. In order to evaluate if the decrease of glycogen in the presence of the antagonist might be due to a reduction of glucose uptake, the expression of GLUT-3 (Figure 5C) and the ability of GSCs to incorporate a D-glucose analog (2NBDG) (Figure 5D) were investigated. GLUT-3 was overexpressed in hypoxia and GW6471 decreased the fluorescence intensity for the transporter paralleled by a decrease of glucose intake in both normoxic and hypoxic conditions. As regard lipid metabolism, the amount of LD (Figure 6A), the expression of Fatty Acid Binding Protein 7 (FABP7) and PPAR $\gamma$ (Figure 6B) and its localization (Figure 6C) and the enzymes of cholesterol synthesis by qReal Time PCR (Figure 6D) were investigated under GW6471 treatment. We observed a strong reduction of LDs in treated cells both in normoxia and in hypoxia, at $8 \mu \mathrm{M}$ and $16 \mu \mathrm{M}$, respectively. Moreover, FABP7, responsible for the uptake and transport of fatty acids, marker of GSCs [33] and known to be regulated by PPAR $\alpha$ [34], was upregulated in hypoxia and significantly downregulated in this condition upon the antagonist treatment. The higher levels of FABP7 in hypoxia were paralleled by the accumulation of LDs in hypoxic cells (Figures $3 \mathrm{E}$ and $3 \mathrm{~F}$ ). Finally, the analysis by qRT-PCR of the enzymes of the mevalonate pathway (Figure 6D) showed that the mRNA levels for HMG-CoA reductase (HMGCR), Farnesyl diphosphate synthase (FDPS), Farnesyl diphosphate farnesyltransferase 1 (FDFT1) or squalene synthase and geranylgeranyltransferase 1 (RABGGTa) did not show significant differences between normoxia and hypoxia, except for mevalonate kinase (MVK) that was upregulated in hypoxic condition. GW6471 remarkably reduced all mRNAs analyzed, both in normoxia and in hypoxia, irrespective of the dose. As regard the mRNA for low-density lipoprotein receptor (LDLR), the GW6471treatment induced a dramatic reduction in normoxia and a dose-dependent decrease in hypoxia. These results suggest that the treatment with the PPAR $\alpha$ antagonist, by inhibiting the MVA pathway, may impair the prenylation of proteins involved in migration and invasion of tumor cells. In addition, it is worth noting that the downregulation of LDLR, upon treatment, may compromise cholesterol influx, important for membrane turnover and for composition of LDs. The analysis of cholesterol content (both free cholesterol and cholesteryl esters) (Figure 6E), showed that normoxic GSCs possess more cholesterol than hypoxic cells and, upon treatment, strong and significant reduction of its level was observed. In hypoxia, the inhibition of PPAR $\alpha$ exerted similar effects with both 8 and $16 \mu \mathrm{M}$, reducing the cholesterol content to about $50 \%$ of its control.

\section{Modulation of PPARs upon GW6471}

The evaluation of the expression pattern of PPAR $\alpha$ and $\gamma$ by western blotting and immunofluorescence, upon GW6471 treatment (Figures 7B and Supplementary Figure 1) showed that PPAR $\alpha$ did not change its localization nor its protein levels in both conditions (Supplementary Figure 1 ), while $\operatorname{PPAR} \gamma$, mainly cytoplasmic in normoxic and hypoxic conditions, was predominantly nuclear after the treatment (Figure 6C). Moreover, at protein level, PPAR $\gamma$, appeared upregulated in dose-dependent manner only in treated hypoxic neurospheres (Figure 6B).

\section{Effect of glucose concentrations on hypoxic GSCs}

All the referred experiments were performed in the standard culture medium, containing $3.15 \mathrm{~g} / \mathrm{L}$ glucose. Since this concentration is higher than that existing inside the tumor, we checked the growth and the metabolic pattern of spheres at at $0.25 \mathrm{~g} / \mathrm{L}$ glucose, which is the concentration of the intratumoral hypoxic microenvironment [35]. In this condition, the effects of $16 \mu \mathrm{M}$ GW6471 treatment were re-evaluated. To this purpose, spheres were grown in a medium containing $3.15 \mathrm{~g} / \mathrm{L}$ (standard medium), $1 \mathrm{~g} / \mathrm{L}$ (physiologic blood levels) and $0.25 \mathrm{~g} / \mathrm{L}$ (interstitial fluid from solid tumor) glucose [9] in hypoxic conditions for $72 \mathrm{hr}$. The BrdU assay showed that GSCs, in the presence of low glucose, were more proliferating than those grown in high glucose (Figure 7A), thus confirming that proliferation is inversely correlated to glucose concentration in the medium [35]. The division frequency of neurospheres, evaluated with the fluorescent dye carboxyfluorescein succimidyl ester 
A

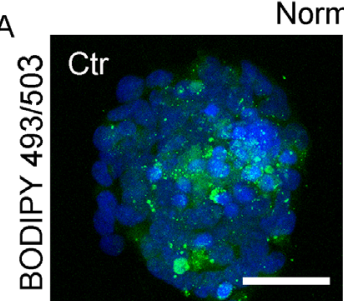

Normoxia

B
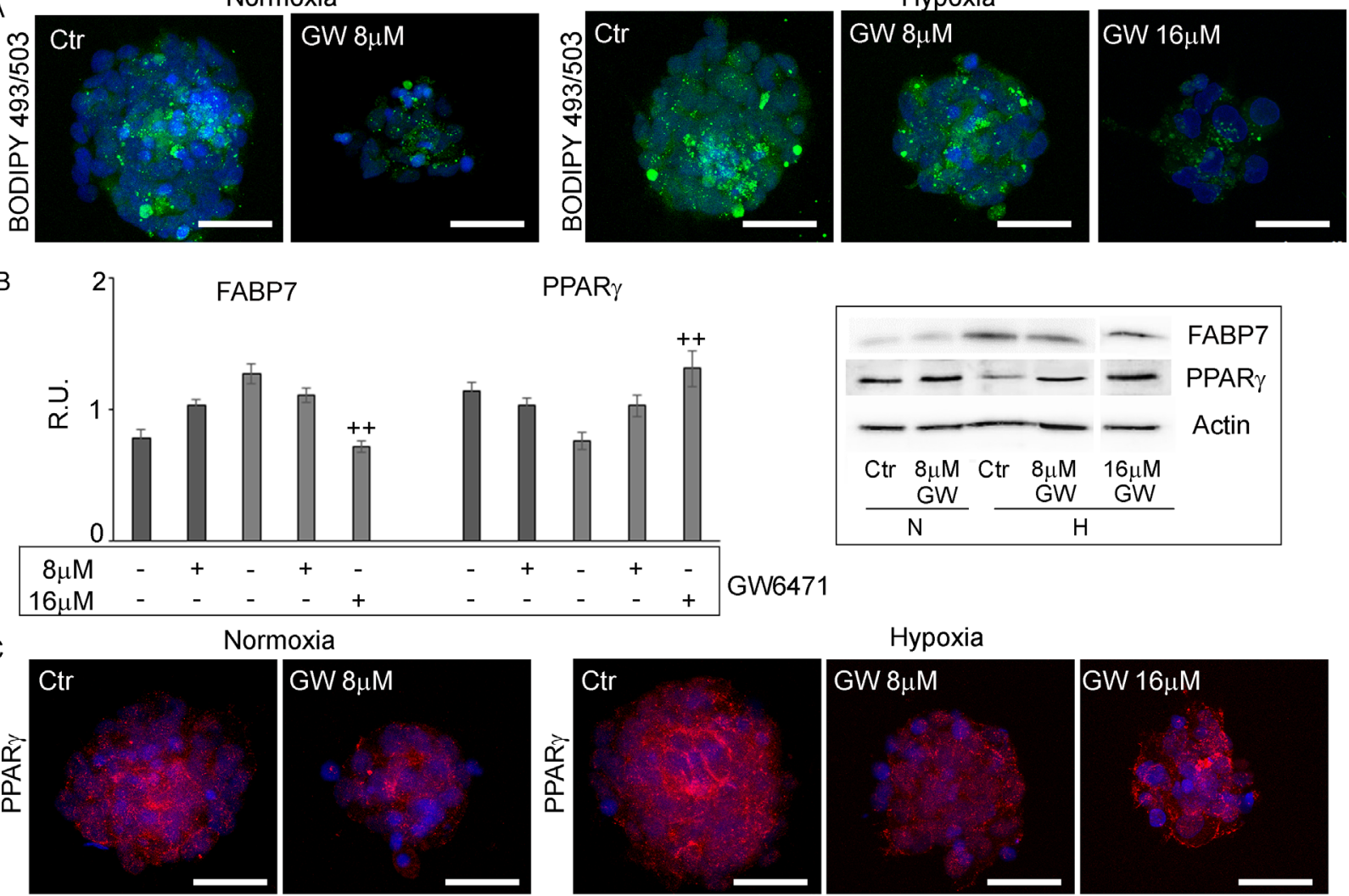

D

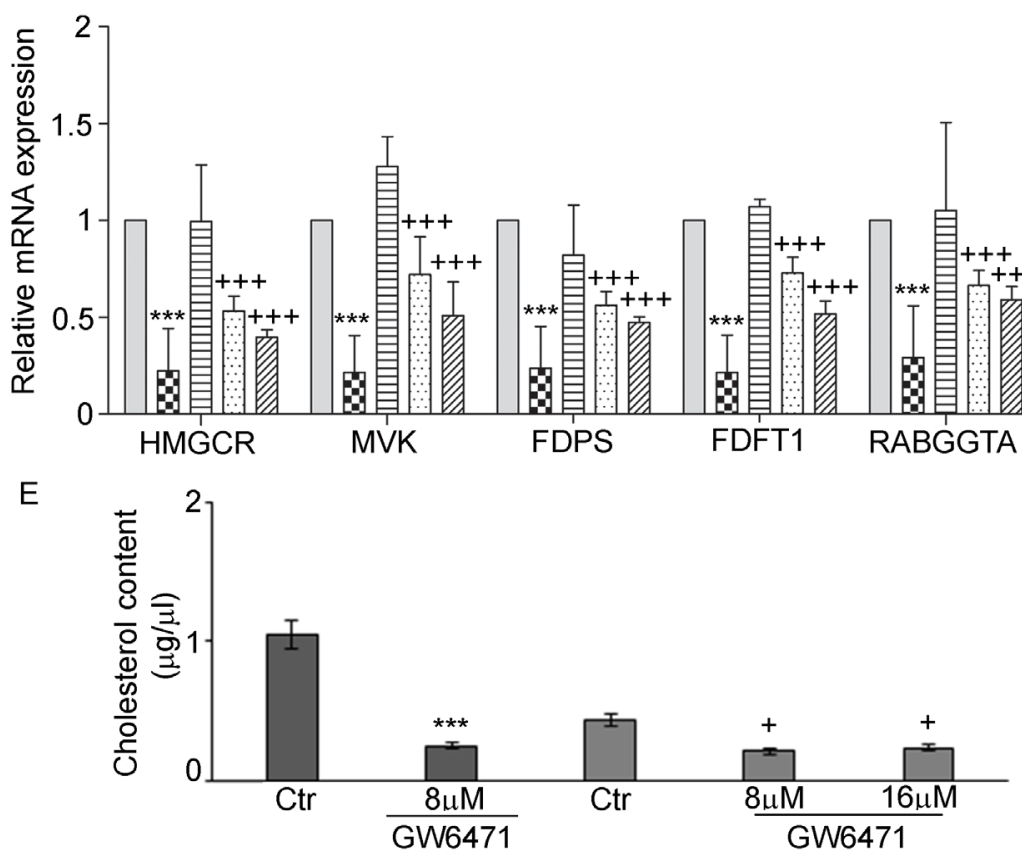

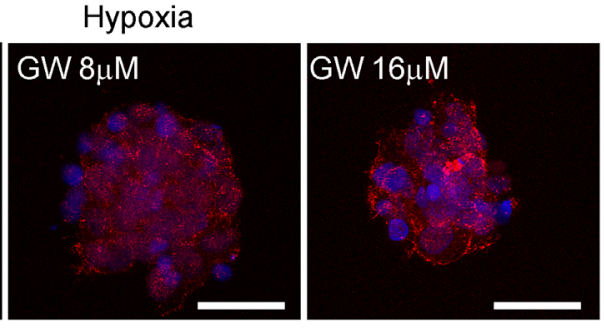
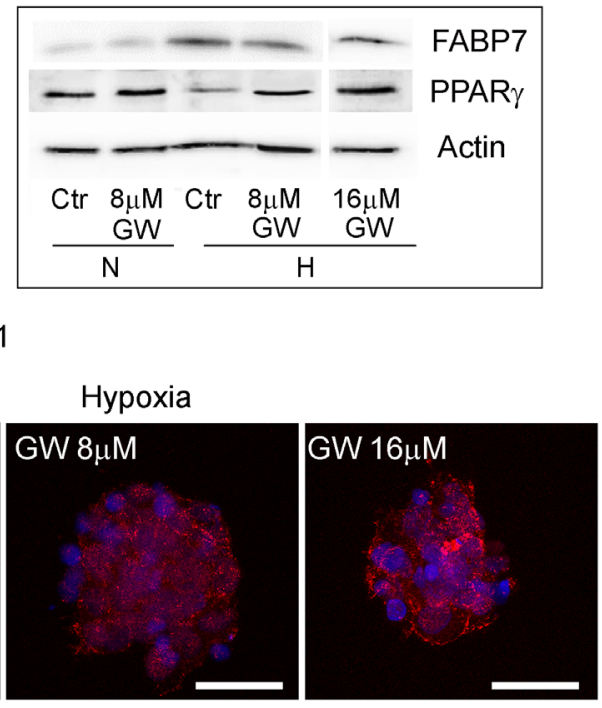

GW6471

\section{Normoxia}

Normoxia+GW8 $\mu \mathrm{M}$

Еypoxia

$\ldots$ Hypoxia+GW8 $\mu \mathrm{M}$

एय] Нypoxia+GW16 $\mu \mathrm{M}$

Figure 6: GW6471 effects on lipid droplets and cholesterol content in normoxic and hypoxic GSCs. A. LD stained with BODIPY 493/503 in treated GSCs shows a significant decrease of LDs in both conditions. Nuclei are stained with Dapi. Bar $=25 \mu \mathrm{m}$. B. Western blotting analysis for FABP7 and PPAR $\gamma$ shows that only in hypoxic condition at $16 \mu \mathrm{M}$, the treatment was able to decrease FABP7 and to increase PPAR $\gamma$. Data are means \pm SD of 3 different experiments.,$++ p<0.001$ hypoxia $v s$ the respective control C. PPAR $\gamma$ immunofluorescence in treated GSCs supports the western blotting results. Nuclei are stained with Dapi. Bar $=25 \mu \mathrm{m}$. D. qRT-PCR analysis of the enzymes of the mevalonate pathway in treated GSCs. Data are means \pm SD of 3 different experiments.,$+++ p<0.0001$ hypoxia vs the respective control, ${ }^{* * *}, p<0.0001$, normoxia with respect to the respective control. E. Cholesterol content in treated GSCs shows a significant decrease of cholesterol content upon treatment in both conditions. Data are means $\pm \mathrm{SD}$ of 3 different experiments.,$+ p<0.01$, hypoxia $v$ the respective control; ${ }^{* *}, p<0.0001$, normoxia with respect to the respective control. 


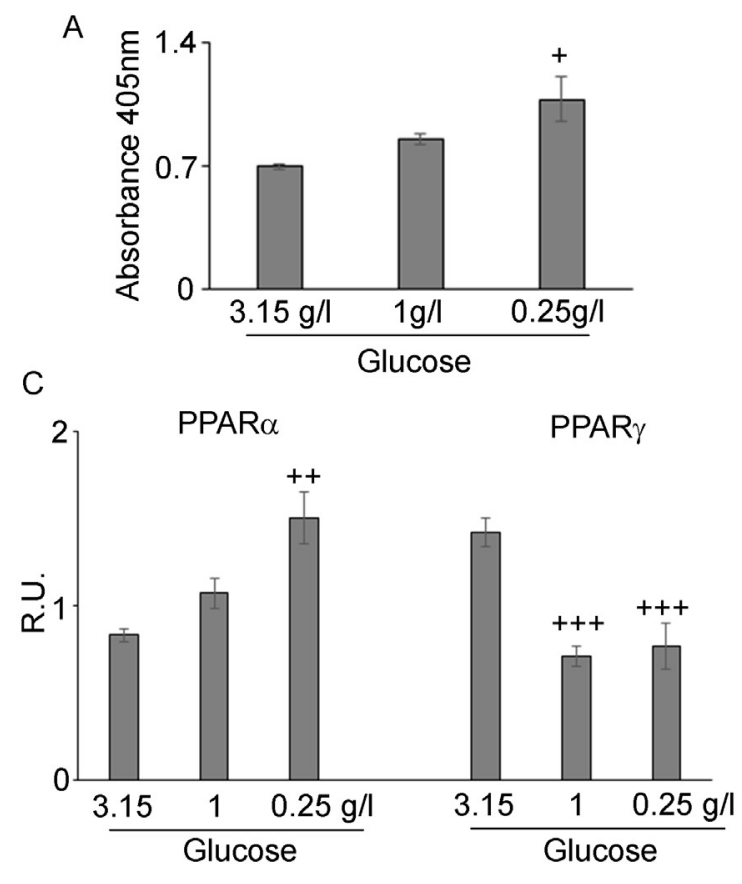

B
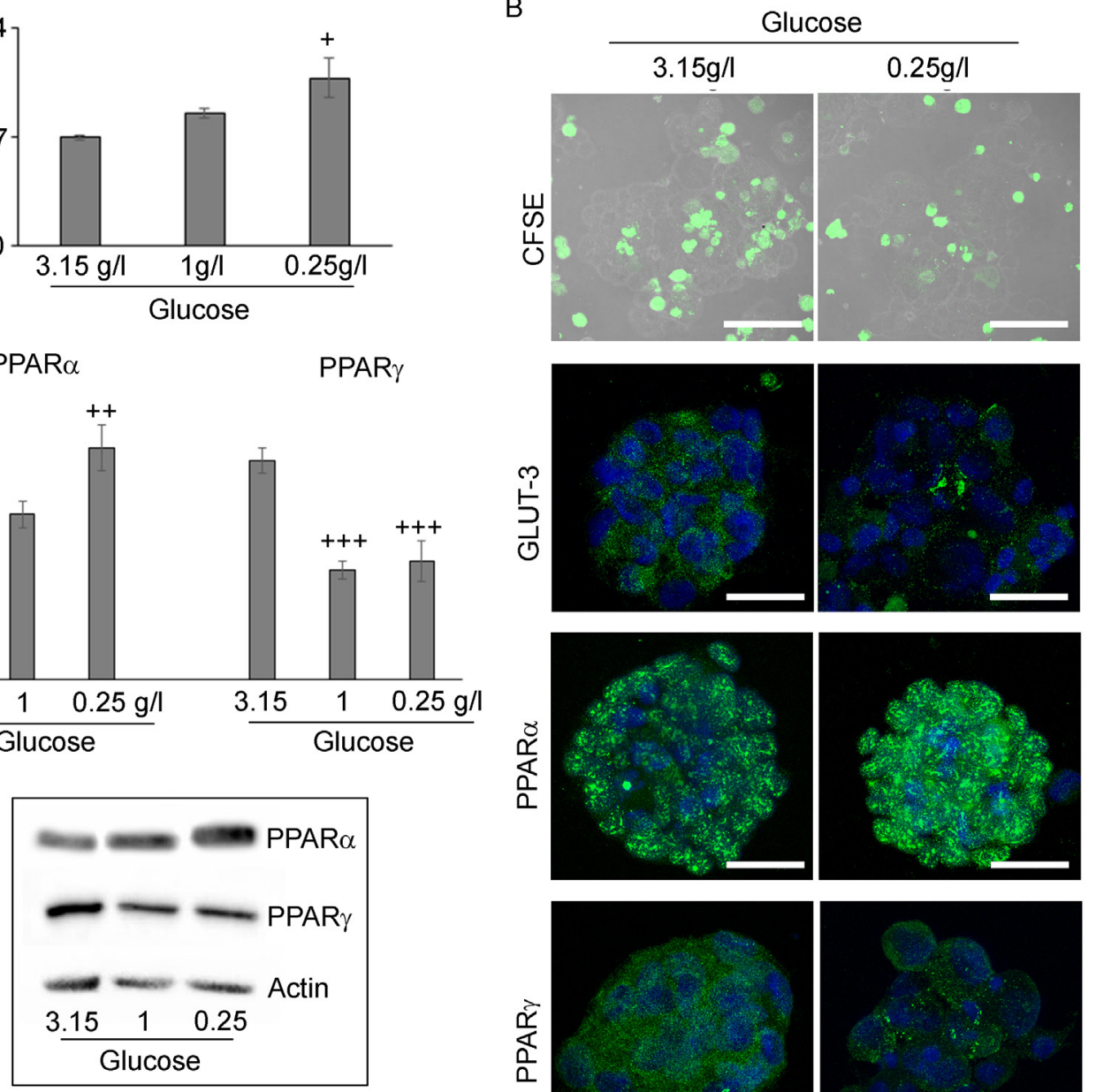

D
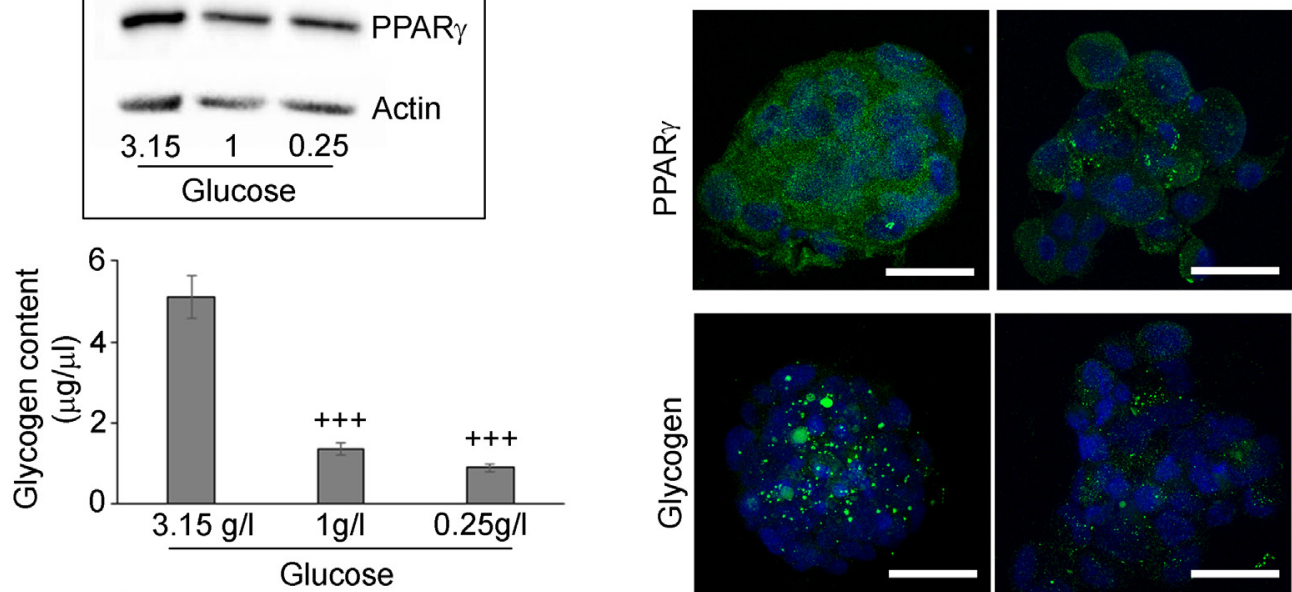

E
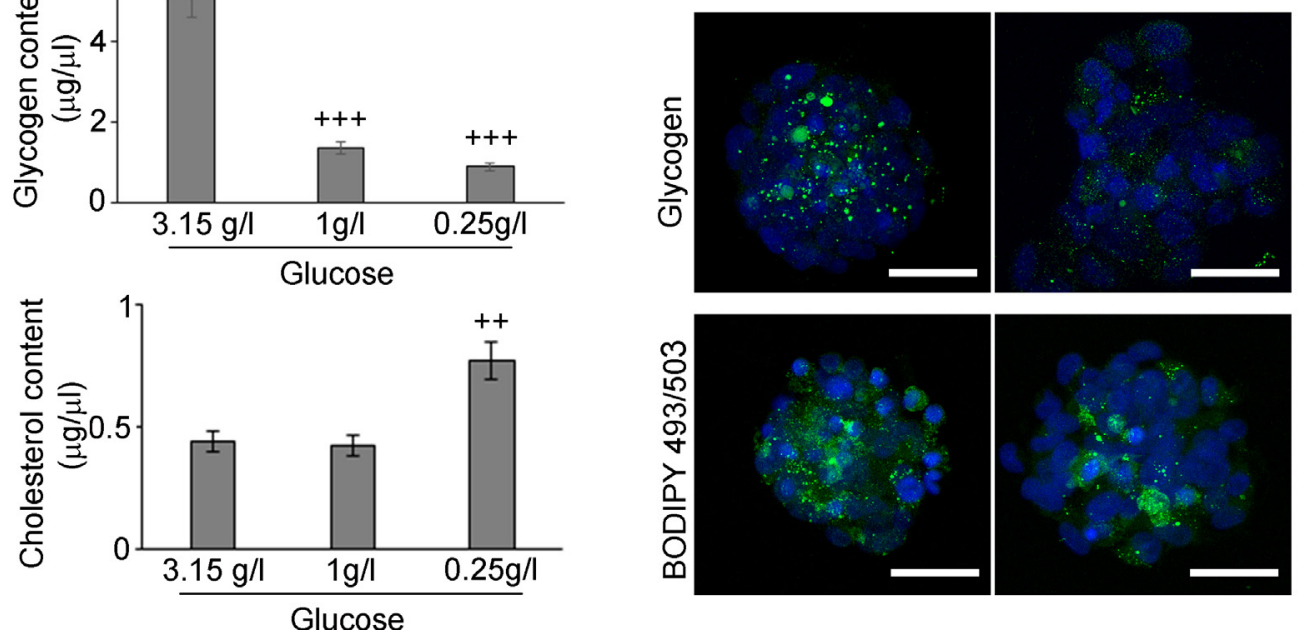

Figure 7: Hypoxic neurospheres grown in restricted glucose conditions. A. BrdU assay of $H$ neurospheres in medium containing $3,15 \mathrm{~g} / \mathrm{L}, 1 \mathrm{~g} / \mathrm{L}$ and $0,25 \mathrm{~g} / \mathrm{L}$ glucose shows that proliferation increase with glucose deprivation. Data are means $\pm \mathrm{SD}$ of 3 different experiments.,$+ p<0.01 v s$ high glucose B. CFSE assay $(\mathrm{Bar}=50 \mu \mathrm{m})$, GLUT3, PPAR $\alpha$ and $\gamma$, glycogen and LD staining in the different glucose conditions shows that the increase of proliferation, PPAR $\alpha$ and a decrease of PPAR $\gamma$, glycogen and GLUT-3 (Bar $=25 \mu \mathrm{m})$. C. Western blotting analysis of PPAR and $\gamma$ confirmed the immunofluorescence data. Data are means \pm SD of 3 different experiments. ,$++ p<0.001 ;+++, p<0.0001$ with respect to high glucose condition. D. Glycogen assay in the different glucose conditions shows a reduction of glycogen content in glucose deprivation. Data are means $\pm \mathrm{SD}$ of 3 different experiments.,$+++ p<0.0001$ with respect to high glucose condition. E. Cholesterol content in the different glucose conditions shows a significant increase of cholesterol content in glucose deprivation. Data are means $\pm \mathrm{SD}$ of 3 different experiments.,$++ p<0.001$ with respect to high glucose condition. 
(CFSE) and analyzed by confocal microscopy (Figure 7B), showed that, the number of cells retaining the dye was higher in high glucose medium, than those grown in low glucose, demonstrating higher proliferation rate in the latter condition. Moreover, it is worth noting that, in high glucose condition, CFSE-positive cells, resided mainly in the hypoxic core of spheres, indicating that the core is slowly-dividing with respect to the remaining cells of the spheres. In $0.25 \mathrm{~g} / \mathrm{L}$ glucose condition, the cells in the core were more proliferating, as demonstrated by their lower fluorescence intensity. The immunofluorescence and western blotting analysis for PPAR $\alpha$ and $\gamma$ showed that, while PPAR $\alpha$ was significantly upregulated at $0.25 \mathrm{~g} / \mathrm{L}$ glucose, the $\gamma$ isotype was strongly downregulated in both $1 \mathrm{~g} / \mathrm{L}$ and $0.25 \mathrm{~g} / \mathrm{L}$ glucose conditions (Figures $7 \mathrm{~B}$ and $7 \mathrm{C}$ ). These data suggest that the expression of these transcription factors is strictly related to the glucose concentration in the medium and that the high proliferation rate of GSCs grown in low glucose may be due to the upregulation of the $\alpha$ isotype. Interestingly, both glycogen and lipid storages were influenced by the glucose concentration, their levels being modulated at low glucose concentration, as demonstrated by immunofluorescence (Figure 7B) and by glycogen and cholesterol assays (Figures 7D and 7E). As regard glycogen, a strong decrease of the number of granules at both $1 \mathrm{~g} / \mathrm{L}$ and $0.25 \mathrm{~g} / \mathrm{L}$ glucose, mainly affecting the external cellular layers of neurospheres, was observed (Figure 7B). This result is consistent with the analysis of glycogen content (Figure 7D) that confirmed a significant decrease of glycogen at $1 \mathrm{~g} / \mathrm{L}$ and at $0.25 \mathrm{~g} / \mathrm{L}$. Similarly to glycogen, LD content was influenced by the concentration of glucose in the medium (Figure 7B), decreasing at $0.25 \mathrm{~g} / \mathrm{L}$ glucose and remaining mainly accumulated in the core of the neurospheres. Interestingly, the cholesterol assay (Figure 7E) showed that GSCs grown in low glucose have higher levels of cholesterol than those cultured in high glucose. Since the protein levels of FABP7 did not change in these conditions (data not shown) while PPAR $\alpha$ significantly increased, and PPAR $\gamma$ even decreased, we hypothesize that the reduction of LDs at $0.25 \mathrm{~g} / \mathrm{L}$ may be due to increased acyl-CoA- $\beta$-oxidation with production of acetyl-CoA to be utilized for the synthesis of cholesterol. Moreover, in this context, it is worth-recalling that, besides acyl-CoA $\beta$ oxidase, also HMG-CoA synthase, leading to increased HMG-CoA synthesis, is a PPAR $\alpha$ target gene, [36].

\section{Effect of GW6471 in low glucose conditions}

Finally, we studied the effect of $16 \mu \mathrm{M}$ GW6471 in low glucose conditions $(0.25 \mathrm{~g} / \mathrm{L})$. The BrdU results (Figure 8A) showed that $16 \mu \mathrm{M}$ GW6471 induced an arrest of cell proliferation to about $50 \%$ of control, demonstrating that the drug is effective, as in high glucose conditions. The CFSE assay (Figure 8B), showing that treated cells retained more dye than controls, confirms that they were delayed and/or arrested in their proliferation. Particularly, we observed a gradient of staining intensity, ranging from cells with a more diluted staining, (low rate of proliferation) to those displaying the highest fluorescence intensity, corresponding to cell cycle-arrested or apoptotic cells.. Finally, in addition to its effect on cell proliferation rate, PPAR $\alpha$ antagonist induced a further decrease of glycogen, LDs (Figure 8B) and glycogen and cholesterol content (Figures 8C and 8D), thus indicating that GSCs are induced to consume their energy stores.

\section{DISCUSSION}

The interest on the role of CSCs is increasing due to their involvement in tumor drug resistance and relapse. As in many cancers, CSCs were identified/isolated also in GB [37], the most malignant and aggressive of brain tumors [1]. It is known that GSCs are a heterogeneous population present in both intratumoral perivascular and necrotic/ hypoxic niches. These microenvironments, maintain stemness, regulate proliferation, self-renewal and fate and protect them from environmental insults [2] resulting from the imbalance between the tumor growth and the vascular expansion that induces metabolic stress and $\mathrm{O}_{2}$ gradient throughout the tumor mass, with a very low $\mathrm{O}_{2}$ pressure within the intratumoral tissue [38]. Hypoxia plays a crucial role in stem cell biology acting through HIF-1 $\alpha$, responsible for many aspects of malignant progression, being involved in the adaptive response to the environmental changes $[39,7]$. The role of PPARs in the regulation of glucose and lipid metabolism has been studied in different cellular models including brain cells [40-41, 21], the highest glucose and ATP consumer of all cells. Although the expression pattern of PPARs has been described in several tumors including gliomas [15], their role in tumorigenesis is still debated.

Therefore we evaluated the presence of PPARs, particularly $\alpha$ and $\gamma$ isotypes, in GSCs, isolated from GB specimens exposed to hypoxia. We demonstrate that hypoxia upregulates HIF- $1 \alpha$ protein and enhances GSC proliferation and induces high levels of PPAR $\alpha$, even increased with respect to normoxic cells. The nuclear localization of PPAR $\alpha$ suggests that it is transcriptionally active and influences GSCs proliferation, as observed also in breast cancer cell lines [24]. On the contrary, PPAR $\gamma$ is downregulated, although not significantly, in hypoxia with a prominent cytoplasmic localization.

To correlate the expression of these receptors to the peculiar glucose and lipid metabolism of GSCs, their glycogen and lipid stores were analyzed, in normoxic and hypoxic conditions. Despite its relatively low levels in the adult brain, as compared to peripheral tissues, glycogen is the largest energy reserve of the CNS. It represents an advantageous form of glucose storage, as it can be rapidly mobilized without requirements for ATP and, differently from fatty acids, it can yield ATP under 
A

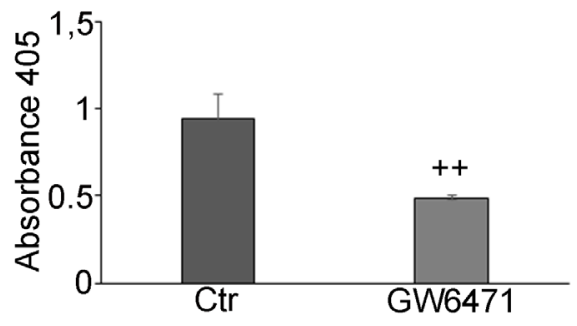

B
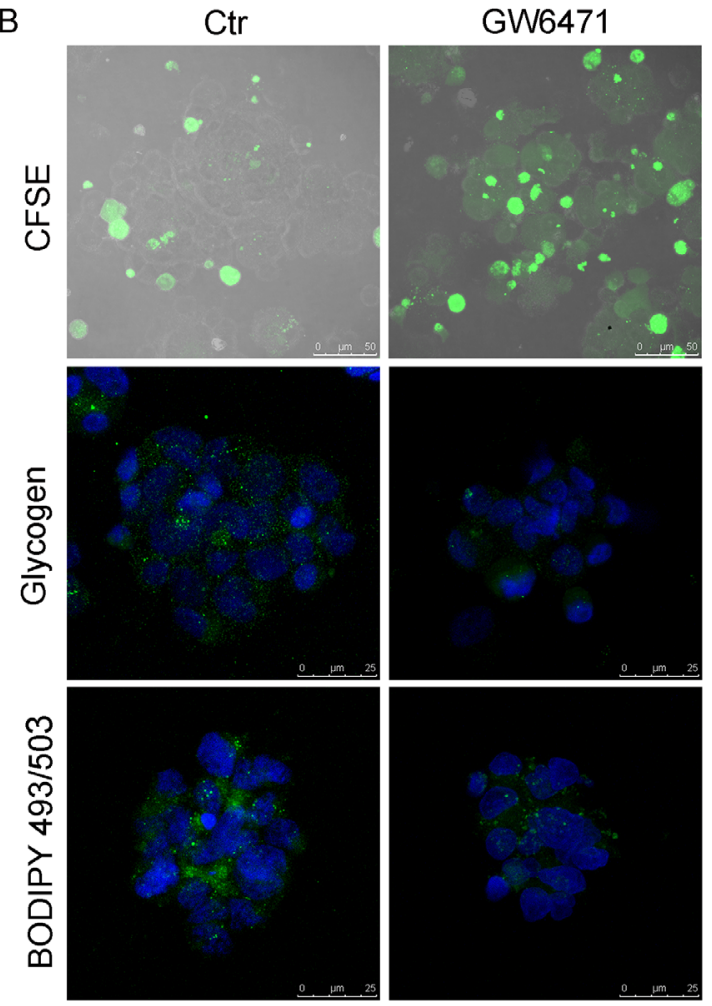

C
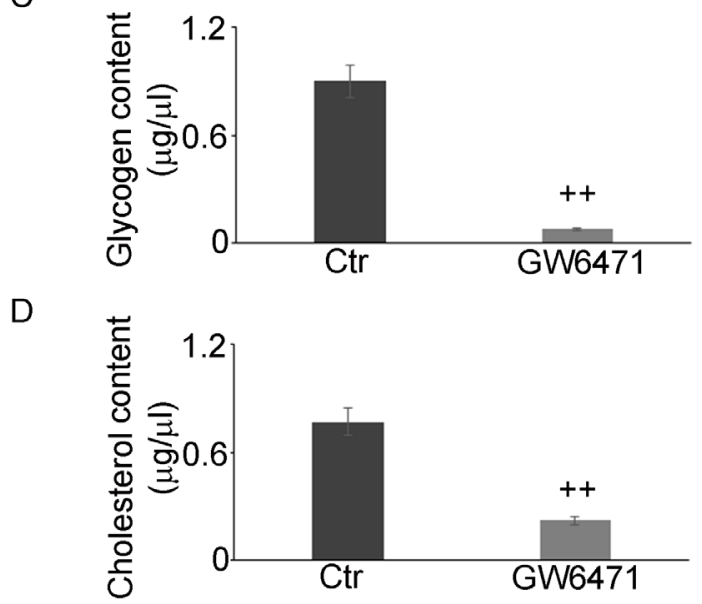

Figure 8: GW6471 effects on proliferation, glycogen and LD storage under glucose shortage. A. BrdU assay of hypoxic neurospheres grown in $0.25 \mathrm{~g} / \mathrm{L}$ glucose and treated with $16 \mu \mathrm{M}$ antagonist shows a significant decrease of proliferation upon treatment. Data are means \pm SD of 3 different experiments.,$++ p<0.001 v s$ control condition (not treated). B. CFSE assay (Bar $=50 \mu \mathrm{m}$ ) and glycogen and LD staining shows a decrease of proliferation, glycogen and LD upon treatment $(\mathrm{Bar}=25 \mu \mathrm{m})$. C. Glycogen content analysis shows a significant decrease of glycogen upon treatment. Data are means \pm SD of 3 different experiments.,$++ p<0.001 v s$ control condition (not treated). D. Cholesterol content decreases upon treatment. Data are means $\pm \mathrm{SD}$ of 3 different experiments.,$++ p<0.001$ vs control condition (not treated). 
anaerobic conditions. In this way glycogen metabolism ensures protection against hypoglycemic neural injury and maintains neurons and axons function during intense periods of activation [42]. The observation of glycogen storages in GB neurospheres is a novel finding for these cells. The granules were found to be more abundant in hypoxia than in normoxia as also confirmed by the increased number of glycogen-positive cells in hypoxic condition. These results suggest that hypoxia may trigger glucose storage in glycogen. In fact, as previously demonstrated both in non malignant and in cancer cells, the hypoxia may act, in an early pro-survival condition, as a warning signal for cell to anticipate the extreme conditions [43]. Glycogen metabolism may represent a survival pathway, by which cells can accumulate energy reserve that can be quickly utilized under more drastic, nutrient-limiting conditions [44]. Parallel findings showed that hypoxia, through HIF-1 $\alpha$, induces the expression of genes encoding the enzymatic proteins required to convert glucose to glycogen, such as glycogen synthase [43-46]. The evaluation of the expression of the active and inactive form of GSK3 $\beta$, involved in the regulation of glycogen synthase activity, demonstrates that the active form of the protein is downregulated, while its inactive form is upregulated in hypoxic condition. It is conceivable that hypoxia, by promoting the phosphorylation and inactivation of the GSK3 $\beta$, may enhance the expression and/or the activity of glycogen synthase. GSCs express the high affinity glucose transporter, GLUT-3 that is increased in hypoxia. In fact, it is shown that HIF-1 $\alpha$ regulates the expression of GLUT-3 [47] and that their coexpression in glioma is significantly correlated with the tumor pathological grade [48]. Therefore, hypoxia may directly regulate cellular glycogen storages by increasing the expression of glucose transport also in GSCs. Through this mechanism GSCs manage to have access to nutrients even in hostile microenvironment, driving tumor growth and survival $[35,49]$. It is noteworthy in this context to recall that: i) PPAR $\alpha$ is highly expressed in GB cells, paralleling malignancy grade [30]); ii) treatment of $A \beta$ loaded hippocampal neurons with a PPAR $\alpha$ agonist, beside improving their survival, increases $\beta$-catenin stabilization, thus suggesting activation of Wnt canonic pathway [50]; iii) recent paper from Cisternas et al. [51] demonstrates that this pathway is involved in glucose utilization and glycolitic metabolism. Thus, it is tempting to speculate that low $\mathrm{O} 2$ and glucose concentrations, existing inside GB mass, induce an adaptive response involving also PPAR $\alpha$, leading to glucose and fatty acid utilization as energy fuels for GSC survival.

Since several studies reported that lipid levels in malignant gliomas are higher than normal tissues [14, 30, 52], the presence of lipid stores in the form of LDs was studied. Massive LD accumulation in GSCs was observed under hypoxic conditions, as also described in human hypoxic mesenchymal stem cells, exhibiting adipocyte- like phenotype with cytoplasmic accumulation of lipids [52]. Moreover, in hypoxic neurospheres, we observed upregulation of perilipin, possibly induced by $\operatorname{PPAR} \alpha$, similarly to human hepatocytes treated with PPAR $\alpha$ agonists [34].

This paper demonstrates that GSCs proliferation and survival and their metabolic signature are PPAR $\alpha$ dependent. In fact, a specific antagonist of this isotype, GW6471, negatively affected cell proliferation and induced apoptosis, leading to reduced number and sizes of spheres. The hypoxic neurospheres were more resistant to the treatment than normoxic ones and required higher concentration of the antagonist. We interpreted this result on the basis that the higher levels of PPAR $\alpha$ in hypoxic neurospheres together to hypoxia itself may contribute to this resistance. As a whole, our data confirm that GW6471 has a cytostatic and cytotoxic effect in GSCs, as in breast and renal cancer cell lines [24-25], and suggest that PPAR $\alpha$ may control GSCs proliferation and survival. Notably, our results suggest that PPAR $\alpha$ is involved in the process of synthesis and demolition of glycogen as its inhibition determines a decrease of its content. While in normoxia the reduction of glycogen content may be mainly due to an increase of glycogenolysis, in hypoxia it may be dependent on both the blockade of glycogen synthesis and the increase of its demolition. The demonstration that glycogen synthase- 2 is a PPAR $\alpha$ target gene in rat and mouse primary hepatocytes [53] and that the synthesis of glycogen is affected in PPARa ${ }^{-/-}$ mice [54] support our hypothesis. It is noteworthy that both Hexokinase II and PKM2, target genes of HIF-1 $\alpha$, are upregulated in hypoxia with respect to normoxia. These data suggest that GSCs have an active glycolysis in hypoxia, thus supporting both the bioenergetics and biosynthetic pathways [52]. In addition, hexokinase, other than to be involved in glycolysis and glycogen synthesis, has a role in protecting cells against apoptosis [55]. Our results show that the hypoxic neurospheres are less prone to apoptosis upon GW6471 treatment, being endowed with higher HEKII levels.

Interestingly we observed that GSCc, which express high levels of GLUT-3 in hypoxia, uptake more glucose in this condition than in normoxia and that the antagonist treatment reduces the influx of glucose in both conditions. Therefore we hypothesize that the reduced uptake of glucose, may be due to the reduced expression of GLUT3 , and may be correlated to the inhibition of PPAR $\alpha$. GW6471 indeed seems to force cells to consume their glycogen reservoir.

Several findings report that hypoxia induces the expression of genes involved in fatty acid uptake and intracellular lipid accumulation and impairs cholesterol metabolism [9, 56]. Particularly, FABP7, involved in fatty acids uptake, is induced by HIF-1 $\alpha$, leading to the accumulation of LDs and contributing to cancer cell growth [33]. Accordingly, our results show enhanced 
expression of FABP7, accumulation of LDs and increase of GSCs proliferation in hypoxia. In this condition, $\operatorname{PPAR} \gamma$, a regulator of adipogenesis, did not significantly change, thus resulting not involved in lipid accumulation as described in mesenchymal stem cells, where the hypoxic stimulus did not induce the expression of genes markers of mature adipocytes, including PPAR $\gamma$ [57]. Our results are also in agreement with Bensaad et al. [56] demonstrating that lipid storage in hypoxia is due to fatty acid uptake, rather than to de novo lipid synthesis.

As regard cholesterol content we found that hypoxic cells exhibited less cholesterol than normoxic ones, although the levels of mRNA of MVA enzymes and of LDL-receptor are not altered in both conditions. A possible explanation is that LDs in hypoxic GSCs may contain intermediates of mevalonate pathway such as squalene, lanosterol and lathosterol, as observed in a hypoxic GB cell line, where these intermediates accumulate since their conversion to cholesterol is oxygen-dependent [58]. In addition, also LDs of mutant yeast strains, used as a model for anaerobic growth, consist of squalene together with triacylglycerols and sterylesters. Both in yeasts and in mammalian cells the stored squalene is involved in clustering and distribution of LDs [58].

GW6471 treatment negatively affected the content of LDs, FABP-7, MVA enzymes, LDLR, cholesterol and cell proliferation. In normoxia, the antagonist reduced the levels of LDs by inhibiting the synthesis and uptake of cholesterol rather than fatty acid influx, since FABP7 levels did not change. Conversely, in hypoxia, the treatment affected both cholesterol and triglyceride content, blocking the MVA pathway and decreasing the levels of LDL receptor and FABP7. Therefore, we propose that the composition of LDs may be different in normoxic and hypoxic neurospheres. As regard mRNA for LDLR, the treatment was effective both in hypoxia and normoxia, downregulating the receptor and impairing the intracellular influx of cholesterol needed for cell membrane turnover and for LD storage.

Since MVA pathway is crucial for GB cell survival and growth, its inhibition by the PPAR $\alpha$ antagonist contributes to cell death induction, cell cycle arrest and repression of cancer cell migration [59]; in fact, statins commonly used in the treatment of hypercholesterolemia, were also used to inhibit cancer [60]. Our results indicate that the inhibition of PPAR $\alpha$ by GW6471 may produce effects similar to statins, down-regulating MVA pathway and up-regulating PPAR $\gamma$. The association of statins and $\operatorname{PPAR} \gamma$ agonists were largely used for cancer treatment [60]

All the above results were obtained with GSCs grown in high glucose levels. Noteworthy, patients with GB are at particular risk of hyperglycemia, because their peritumoral edema is regularly treated with high-dose of glucocorticoids, which are known to increase plasma glucose [61]. Hyperglycemia, by activating various signaling pathways that control cancer cell behavior such as proliferation, migration, invasion and recurrence [62] and providing an extra energetic fuel, promotes tumor growth [63] by supporting the high glycolytic metabolism of GB. In this paper, we also compared hypoxic GSCs grown in standard culture conditions to hypoxic GSC grown in restricted glucose concentration, which is more representative of the interstitial fluid in solid tumors, thus mimicking the in vivo situation. Indeed, tumor microenvironment associated with hypoxia and nutrient restriction may be important in the regulation of tumor progression.

It is known that, as result of the inhibition of angiogenesis, cancer cells exposed to both hypoxia and starvation, are induced to be more aggressive [64]. Differently to hypoxia, nutrient depletion has not been well investigated in terms of its effect on cancer stem cells. Nutrient limitations within solid tumors may require that malignant cells exhibit metabolic flexibility to sustain growth and survival [65].

On the basis of these considerations, we investigated the impact of glucose shortage on proliferation and metabolic pattern of hypoxic neurospheres and the effect of GW6471 on GSCs growth/survival in restricted glucose levels. We confirm that glucose restriction contributes to tumor progression since the GSCs grown at low glucose levels were higly proliferating and paralleled by a significant increase of PPAR $\alpha$ and decrease of PPAR $\gamma$, thus confirming the opposite role of the two nuclear transcription factors in GSCs.

It is intriguing to underline that glucose metabolic rate and uptake did not correlate with GLUT3 expression but with cell proliferation. In fact, GLUT3 did not significantly change, switching from high $(3,15 \mathrm{~g} / \mathrm{L})$ to restricted $(0.25 \mathrm{~g} / \mathrm{L})$ glucose. In response to glucose reduction, GSCs utilize their glycogen storage to support metabolic and survival pathways in stressful conditions [43-44]. Moreover, GSCs grown in restricted nutrients decreased their LD content and increased their cholesterol content to sustain the high cell proliferation rate. We suggest that, since the uptake of fatty acids was not influenced by the different glucose concentrations, the upregulation of PPAR $\alpha$ in the restricted glucose condition may also lead to the induction of the $\beta$-oxidation of fatty acids producing acetyl-CoA to be utilized for the synthesis of cholesterol. In this condition GW6471 induces, similarly to what observed in high glucose condition, an inhibitory effect on cell proliferation and on glycogen, LDs and cholesterol content.

In conclusion, our data support, for the first time, a crucial role of PPAR $\alpha$ in regulating the metabolic switch that allows GSCs to survive in $\mathrm{O} 2$ and nutrient limitations and demonstrate the effectiveness of GW6471 as antitumor and lipid/glucose storage-reducing drug. Targeting specific metabolic pathways essential to GSCs survival is a new and promising approach against cancer. We here 
propose the use of GW6471 as a potential novel strategy for targeting GSCs to be associated with the gold standard protocols.

\section{MATERIALS AND METHODS}

\section{Sample classification}

GSCs were isolated from post-surgical specimens of patients with diagnosis of Grade IV glioma, from S. Salvatore Hospital, L'Aquila, Italy. All samples were classified according to the World Health Organization guidelines (WHO). This study was ethically approved (Hospital Ethics Committee), and all patients were voluntary signing an informed consent

\section{Neurospheres primary culture}

Tumor samples, were dissected, dissociated, incubated in HBSS solution containing 0.125\% Trypsin, $0.125 \%$ EDTA and $0.2 \mathrm{mg} / \mathrm{ml}$ DNAse (Sigma Chemical St. Louis, CO), at $37^{\circ} \mathrm{C}$, for $20 \mathrm{~min}$ and cultured, until formation of primary tumorsphere, in Dulbecco's modified Eagle's medium/F-12 medium (DMEM-F12, Sigma), containing 100 units $/ \mathrm{ml}$ penicillin/streptomycin, $2 \mathrm{mM}$ glutamine (Sigma), 2\% B27 supplement (Invitrogen Corporation, CA, USA) and $20 \mathrm{ng} / \mathrm{mL}$ of both epidermal growth factor (EGF) and fibroblast growth factor (FGF2) (Peprotech, Rocky Hill, NY), at $37^{\circ} \mathrm{C}$ in humidified 95\% air-5\% $\mathrm{CO}_{2}$ atmosphere.

Primary spheres were dissociated mechanically and plated at a density of $2500-5000$ cells $/ \mathrm{cm}^{2}$ for several passages (clonal selection).

Isolated neurosheres were assayed for their stemness properties in terms of immunopositivity to stem cell markers by immunofluorescence and cytofluorimetry.

\section{Hypoxia}

Hypoxia was performed into a hypoxic chamber, Galaxy 14S CO2 incubator, (New Brunswick Scientific, Edison, USA) with a gas mixture of $94 \% \mathrm{~N}_{2}, 5 \% \mathrm{CO}_{2}$ and $1 \% \mathrm{O}_{2}$, for $72 \mathrm{hr}$, at $37^{\circ} \mathrm{C}$.

\section{Cell proliferation by BrdU assay}

Neurospheres proliferation was assayed by the incorporation of BrdU. Single cells from neurospheres $\left(5 \times 10^{3}\right.$ cells/well) were grown for 5-7 days and incubated with BrdU labeling and detection kit III (Roche, Basel, Switzerland) for $72 \mathrm{hr}$. following the manufacturer's instructions. The absorbance of the samples (405 nm) was measured with a spectrophotometric microplate reader
(Infinite F200 Tecan, Switzerland).

\section{Immunofluorescence}

Neurospheres were allowed to adhere on polyL-lysine coated glass coverslips $(15 \mu \mathrm{g} / \mathrm{ml})$, fixed with $4 \%$ paraformaldehyde in PBS, for $10 \mathrm{~min}$, at RT and incubated with following antibodies: monoclonal antinestin (1:100, Chemicon International, Temecula, CA, USA), anti-CD133/1 (1:50, Miltenyl Biotec. Inc., Auburn, CA, USA), anti- $\beta$-tubulin III (1:500, Promega, Mannheim, Germany), polyclonal anti-SOX2 (1:500, Abcam) and anti-GFAP (1:200, Sigma), rabbit antiHIF-1 $\alpha$ (1:200, Santa Cruz, CA, USA), anti-PPARa and anti-PPAR $\gamma$ (1:400, Thermo Scientific Inc., USA), antiGLUT3 (1:100, Abcam, Cambridge, UK) and mouse IgM anti-glycogen (1:400, generous gift from Prof. Yoshinobu Baba, Nagoya University). Primary antibodies were revealed by Alexa Fluor 488 or 633 anti-rabbit IgG or Fluorescein Isothiocyanate (FITC) anti-mouse IgM secondary antibody (Sigma).

For bodipy staining, neurospheres were incubated with 4,4-difluoro-1,3,5,7,8-pentamethyl 4-bora-3a,4adiaza-sindacene $(1 \mu \mathrm{g} / \mathrm{mL}$, BODIPY 493/503 Molecular Probes, Invitrogen), for $10 \mathrm{~min}$, at RT. Coverslips were mounted with Vectashield Mounting Medium with Dapi (Vector Laboratories, Burlingame, CA, USA) and examined at a Leica TCS SP5 confocal microscope (Mannheim, Germany).

\section{Cytofluorimetric analysis}

\section{Flow cytometry analysis of neurospheres cultures}

The dissociated neurospheres were examined by FACSCalibur flow cytometry (BD Instruments Inc., USA) for detection of following markers: $\beta$-tubulin III (Alexa Fluor 488), anti-SOX-2 (PE Mouse), anti-nestin (Alexa Fluor 647) - all acquired from Becton Dickinson (BD) anti-GFAP (Glial fibrillary acidic protein, Sigma-Aldrich) and anti-CD133 (anti-PROM-1, Abnova).

The single-cell suspensions $\left(0.5 \times 10^{6}\right.$ cell/tube $)$ were washed, fixed, for $15 \mathrm{~min}$ at RT, with $2 \%$ formaldehyde in PBS and permeabilized for 5 min with Triton X-100 at RT for intracellular markers. Cells were washed with PBS and then incubated, for $1 \mathrm{~h}$, at RT, with selected primary antibodies for $1 \mathrm{~h}$ at RT in the dark. For CD133 and GFAP detection, secondary PE (Abcam) and FITC-conjugated (Millipore) antibodies respectively were used for $1 \mathrm{~h}$ at RT. The population of interest was gating according to its Forward Scatter (FSC)/Side Scatter (SSC) criteria. 10,000 events were acquired for each sample and analyzed by CellQuest software (BD Instruments Inc., USA). 
Table 1: Specific primer sets

\begin{tabular}{|l|c|c|}
\hline \multicolumn{2}{|c|}{ RT-PCR primers } \\
\hline Gene symbol & Forward Primer & Reverse Primer \\
\hline HMGCR & 5'-taccatgtcaggggtacgtc-3' & 5' -ccagtcctaatgaaaccttagaag-3' \\
\hline MVK & 5'-gctcaagttcccagagatcg-3' & 5'-atggtgctggttcatgtcaa-3' \\
\hline FDPS & 5'-agcaggatttcgttcagcac-3' & 5'-tcccggaatgctactaccac-3' \\
\hline FDFT1 & 5'-ggtcccgctgttacacaact-3' & 5'-aaaactctgccatcccaatg-3' \\
\hline RABGGTA & 5'-gacccctgctgtatgagaa-3' & 5'-cacctcggcatactccatct-3' \\
\hline LDLR & 5'-gaatttggccagacacaggt-3' & 5'-caccgtacccagctgatttt-3' \\
\hline$\beta 2 M$ & 5'-cctggattgctatgtgtctgg-3' & 5'-ggagcaacctgctcagataca-3'
\end{tabular}

\section{Glycogen content}

Single cells from neurospheres were fixed with $2 \%$ formaldehyde in PBS, for 15 min, at RT and permeabilzed with TX-100 0.1\% (Sigma). Cells were incubated with mouse IgM anti-glycogen (1:200) antibodies for $1 \mathrm{~h}$, at RT, recognized by FITC anti-mouse IgM secondary antibodies and evaluated using a FACS Calibur cytometer analyzer (Becton Dickinson, San Diego, CA, USA). Data were analyzed using CellQuest software (Becton Dickinson).

\section{PPAR $\alpha$ antagonist treatment}

BrdU labeled cells were treated with different

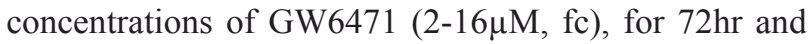
incubated in normoxia and hypoxia respectively. For immunofluorescence, western blotting and RT-PCR analyses cells were treated with $8 \mu \mathrm{M}$ in normoxia and $8-16 \mu \mathrm{M}$ GW6471 in hypoxia for $72 \mathrm{hr}$.

\section{Apoptosis}

Normoxic and hypoxic neurospheres, treated with $8-16 \mu \mathrm{M}$ GW6471 for $72 \mathrm{hr}$, were processed by Cell Death Detection ELISA ${ }^{\text {PLUS }}$ kit (Roche) following the manufacturer's instructions.

\section{Neurospheres number and size}

For the analysis of spheres formation, single cells from neurospheres were treated with with $8 \mu \mathrm{M}$ GW6471 in normoxia and $16 \mu \mathrm{M}$ dose in hypoxia, for $72 \mathrm{~h}$. After treatment, formed spheres were photographed and counted at contrast phase microscopy.

\section{Western blotting}

Normoxic and hypoxic neurospheres treated or not with GW6471 were lysated in RIPA buffer, sheared through a 22 -gauge needle and centrifuged at full-speed
(Eppendorff microfuge 5418 ), at $4{ }^{\circ} \mathrm{C}$, for $30 \mathrm{~min}$. Proteins were assayed by the bicinchoninic acid protein assay kit (Pierce, Rockford, IL, USA). For glucose transporter, GLUT3, lysates of cell membranes were used as antigen.

Protein lysates $(30-50 \mu \mathrm{g} / \mathrm{lane})$ were separated on $10 \%$ SDS polyacrylamide gel and electroblotted onto polyvinyldifluoride membrane (Sigma). Non specific binding sites were blocked by $5 \%$ non fat dry milk (BioRad Laboratories, Hercules, CA, USA) in Tris-buffered saline (TBS; $20 \mathrm{mM}$ Tris-HCl, $\mathrm{pH}$ 7.4, containing 150 $\mathrm{mM} \mathrm{NaCl}$ ), overnight at $4{ }^{\circ} \mathrm{C}$. Blots were probed with following primary antibodies: rabbit polyclonal antiHIF-1 $\alpha$ (1:200), anti-perilipin A (1:500), anti-adipophilin (1:500), anti-actin (1:2000) (Sigma), anti-glycogen synthase kinase-3 $\beta$ phospho-ser9 (pGSK3 $\beta$, 1:500, Enogene Biotech., Aachen, Germany), anti-glycogen synthase kinase-3 $\beta$ (GSK3 $\beta$, 1: 5000, Abcam), antiGLUT3 (1:5000, Abcam), anti-pyruvate kinase isoenzyme type M2 (PMK2, 1:1000, Abcam), anti-hexokinase II (1:500, Cell Signaling Technology Inc., Danvers MA, USA), anti-fatty acid binding protein 7 (FABP7, 1:500 GeneTex Inc., Irvine, CA, USA) and mouse monoclonal anti-PPAR $\alpha$ (1:200) and anti-PPAR $\gamma$ (1:500) (Novus Biologicals, Littleton, CO, USA), anti-glycogen phosphorylase isoenzyme BB (GPBB,1:1000, Abcam) overnight, at $4{ }^{\circ} \mathrm{C}$. All antibodies were diluted with TBS containing $0.25 \%$ Tween-20 (TTBS) and 5\% non fat dry milk. As secondary antibodies, peroxidase conjugated antirabbit or anti-mouse IgG (1:10000, KPL, Gaithersburg, USA), in TTBS containing $5 \%$ non fat dry milk, were used for $1 \mathrm{~h}$, at RT. Immunoreactive bands were visualized by enhanced chemiluminescence (Cyanagen S.r.l, Bologna, Italy), according to the manufacturer's instructions.

\section{Glucose uptake}

Glucose uptake was evaluated using a fluorescent D-glucose analog 2- [N-(7-nitrobenz-2-oxa-1,3-diazol4-yl)amino]-2-deoxy-D-glucose (2-NBDG Molecular Probe, Invitrogen) as described by [66-67], with some modifications. Neurospheres treated or not with $8 \mu \mathrm{M}$ GW6471 in normoxia and with $8-16 \mu \mathrm{M}$ GW6471 in 
hypoxia, were incubated with complete DMEM-F12 without glucose (Biowest, Nuaille', France), for 1h, at RT (starvation) and incubated with $200 \mu \mathrm{M} 2-\mathrm{NBDG}$, for $1 \mathrm{~h}$, at $37^{\circ} \mathrm{C}$. Control were performed incubating neurospheres with $200 \mu \mathrm{M}$ 2-NBDG in presence of DMEM-F12 containing glucose. After washing with PBS spheres were fixed with 4\% paraformaldehyde in PBS, for $10 \mathrm{~min}$, at RT. Coverslips were mounted with Vectashield Mounting Medium with Dapi (Vector) and examined at a Leica TCS SP5 confocal microscope.

\section{Quantitative real time-PCR (qRT-PCR)}

Neurospheres treated or not with $8 \mu \mathrm{M}$ GW6471 in normoxia and with $8-16 \mu \mathrm{M}$ in hypoxia were harvested with Trizol (Invitrogen) and total RNA was isolated using the Nucleo Spin RNA II kit (Macherey-Nagel) according manufacturer's instructions. cDNA was transcribed using Super Script II Reverse Transcriptase (Invitrogen), starting from 0.5 micrograms of high pure RNA. Mevalonate genes expression profiles were evaluated with specific primer sets (Table 1) and using Sso Fast Eva Green reagents (BioRad), $\beta 2$-microglobulin was used as housekeeping gene. qRT-PCR protocol was: a pre-heating step for $3 \mathrm{~min}$, at $95^{\circ} \mathrm{C}, 40$ cycles at $95^{\circ} \mathrm{C}$ for 10 seconds and $60^{\circ} \mathrm{C}$ for 30 seconds and last end-step at $65^{\circ} \mathrm{C}$ for 10 seconds. Results were analyzed with $2-^{\Delta \Delta \mathrm{Ct}}$ method [68].

\section{Cholesterol assay}

Neurospheres treated or not with $8 \mu \mathrm{M}$ GW6471 were extracted with chloroform:isopropanol:NP40 $(7: 11: 0.1)$ and the organic phase was dried at $50 \mathrm{C}^{\circ}$ and put under vacuum for $30 \mathrm{~min}$. Dried lipids were dissolved with Cholesterol Assay Buffer and assayed according to manufacturer's instructions (Cayman, Michigan, USA). The fluorescence of the samples was measured at Ex/Em = $535 / 590 \mathrm{~nm}$ with a microplate reader (Infinite F200 Tecan, Switzerland).

\section{Cell proliferation by carboxyfluorescein diacetate succinimidyl ester (CFSE)}

Cell proliferation is evaluated by the CellTrace ${ }^{\mathrm{TM}}$ CFSE cell proliferation kit (Molecular Probes, Life Technology, Carlsbad, CA, USA), according to manufacturer's protocol.

Neurospheres were allowed to adhere on polyL-lysine coated glass coverslips and fixed in 4\% paraformaldehyde in PBS, for 10 minutes, at RT. Coverslips were mounted with Vectashield Mounting Medium and examined at a Leica TCS SP5 confocal microscope.

\section{Glycogen assay}

Neurospheres grown in $0.25 \mathrm{~g} / \mathrm{L}$ glucose,and $16 \mu \mathrm{M}$ GW6471 treated were homogenized with ice cold glycogen hydrolysis buffer, for $10 \mathrm{~min}$, centrifuged at $12000 \mathrm{rpm}$, for $5 \mathrm{~min}$ and supernatants were assayed according to manufacturer's instructions (BioVision, Milpitas, CA, USA). The product was revealed at $450 \mathrm{~nm}$.

\section{Statistical analysis}

For statistical analysis samples were processed by SPSS software and analyzed by ANOVA test followed by Scheffe's post hoc test" analysis. ${ }^{*} P<0.05$; $* * P<0.005$, $* * * P<0.0005$. All data are mean $\pm \mathrm{SD}$ of three separate experiments run in triplicate.

\section{ACKNOWLEDGMENTS AND FUNDING}

This work was supported by the RIA funds (Proff Ippoliti, Cifone and Cimini). Many of the experiments have been performed in the Research Center for Molecular Diagnostics and Advanced Therapies granted by the Abruzzo Earthquacke Relief Fund (AERF).

\section{CONFLICTS OF INTEREST}

There is no conflict of interest.

\section{REFERENCES}

1. Mrugala MM. Advances and challenges in the treatment of glioblastoma: a clinician's perspective. Discov Med. 2013; 15:221-30.

2. Fidoamore A, Cristiano L, Antonosante A, d'Angelo M, Di Giacomo E, Astarita C, Giordano A, Ippoliti R, Benedetti E, Cimini A. Glioblastoma Stem Cells Microenvironment: The Paracrine Roles of the Niche in Drug and Radioresistance. Stem Cells Int. 2016; 2016:6809105. https://doi. org/10.1155/2016/6809105

3. Vaupel P. The role of hypoxia-induced factors in tumor progression. Oncologist. 2004 (Suppl 5); 9:10-17. https:// doi.org/10.1634/theoncologist.9-90005-10

4. Jensen RL. Brain tumor hypoxia: tumorigenesis, angiogenesis, imaging, pseudoprogression, and as a therapeutic target. J Neurooncol. 2009; 92:317-35. https:// doi.org/10.1007/s11060-009-9827-2

5. Yang L, Lin C, Wang L, Guo H, Wang X. Hypoxia and hypoxia-inducible factors in glioblastoma multiforme progression and therapeutic implications. Exp Cell Res. 2012; 318:2417-26. https://doi.org/10.1016/j. yexcr.2012.07.017

6. Persano L, Rampazzo E, Basso G, Viola G. Glioblastoma cancer stem cells: role of the microenvironment and 
therapeutic targeting. Biochem Pharmacol. 2013; 85:61222. https://doi.org/10.1016/j.bcp.2012.10.001

7. Semenza GL. HIF-1 mediates metabolic responses to intratumoral hypoxia and oncogenic mutations. J Clin Invest. 2013; 123:3664-71. https://doi.org/10.1172/ JCI67230

8. Menendez JA, Alarcón T. Metabostemness: a new cancer hallmark. Front Oncol. 2014; 4:262. https://doi.org/10.3389/ fonc.2014.00262

9. Sato A, Sunayama J, Okada M, Watanabe E, Seino S, Shibuya K, Suzuki K, Narita Y, Shibui S, Kayama T, Kitanaka C. Glioma-initiating cell elimination by metformin activation of FOXO3 via AMPK. Stem Cells Transl Med. 2012; 1:811-24. https://doi.org/10.5966/sctm.2012-0058

10. Pacini N, Borziani F. Cancer stem cell theory and the warburg effect, two sides of the same coin? Int J Mol Sci. 2014; 15:8893-930. https://doi.org/10.3390/ijms15058893

11. Brante G. Lipids in the nervous system. Acta Physiol Scand. 1949; 18:63.

12. Tosi MR, Tugnoli V. Cholesteryl esters in malignancy. Clin Chim Acta. 2005; 359:27-45. https://doi.org/10.1016/j. cccn.2005.04.003

13. Srivastava NK, Pradhan S, Gowda GA, Kumar R. In vitro, high-resolution $1 \mathrm{H}$ and 31P NMR based analysis of the lipid components in the tissue, serum, and CSF of the patients with primary brain tumors: one possible diagnostic view. NMR Biomed. 2010; 23:113-22. https://doi.org/10.1002/ nbm.1419

14. Guo D, Bell EH, Chakravarti A. Lipid metabolism emerges as a promising target for malignant glioma therapy. CNS Oncol. 2013; 2:289-99. https://doi.org/10.2217/cns.13.20

15. Youssef J, Badr M. Peroxisome proliferator-activated receptors and cancer: challenges and opportunities. $\mathrm{Br}$ J Pharmacol. 2011; 164:68-82. https://doi.org/10.1111/ j.1476-5381.2011.01383.x

16. Chattopadhyay N, Singh DP, Heese O, Godbole MM, Sinohara T, Black PM, Brown EM. Expression of peroxisome proliferator-activated receptors (PPARS) in human astrocytic cells: PPARgamma agonists as inducers of apoptosis. J Neurosci Res. 2000; 61:67-74. https:// doi.org/10.1002/1097-4547(20000701)61:1<67::AIDJNR8>3.0.CO;2-7

17. Morosetti R, Servidei T, Mirabella M, Rutella S, Mangiola A, Maira G, Mastrangelo R, Koeffler HP. The PPARgamma ligands PGJ2 and rosiglitazone show a differential ability to inhibit proliferation and to induce apoptosis and differentiation of human glioblastoma cell lines. Int J Oncol. 2004; 25:493-502.

18. Cimini A, Cristiano L, Colafarina S, Benedetti E, Di Loreto S, Festuccia C, Amicarelli F, Canuto RA, Cerù MP. PPARgamma-dependent effects of conjugated linoleic acid on the human glioblastoma cell line (ADF). Int J Cancer. 2005; 117:923-33. https://doi.org/10.1002/ijc.21272

19. Grommes C, Landreth GE, Sastre M, Beck M, Feinstein
DL, Jacobs AH, Schlegel U, Heneka MT. Inhibition of in vivo glioma growth and invasion by peroxisome proliferator-activated receptor gamma agonist treatment. Mol Pharmacol. 2006; 70:1524-33. https://doi.org/10.1124/ mol.106.022194

20. Spagnolo A, Grant EN, Glick R, Lichtor T, Feinstein DL. Differential effects of PPARgamma agonists on the metabolic properties of gliomas and astrocytes. Neurosci Lett. 2007; 417:72-77. https://doi.org/10.1016/j. neulet.2007.02.036

21. Benedetti E, Galzio R, Cinque B, Biordi L, D'Amico MA, D'Angelo B, Laurenti G, Ricci A, Festuccia C, Cifone MG, Lombardi D, Cimini A. Biomolecular characterization of human glioblastoma cells in primary cultures: differentiating and antiangiogenic effects of natural and synthetic PPARgamma agonists. J Cell Physiol. 2008; 217:93-102. https://doi.org/10.1002/jcp.21479

22. Papi A, Tatenhorst L, Terwel D, Hermes M, Kummer MP, Orlandi M, Heneka MT. PPARgamma and RXRgamma ligands act synergistically as potent antineoplastic agents in vitro and in vivo glioma models. J Neurochem. 2009; 109:1779-90. https://doi.org/10.1111/j.14714159.2009.06111.x

23. Chearwae W, Bright JJ. PPARgamma agonists inhibit growth and expansion of CD133+ brain tumour stem cells. Br J Cancer. 2008; 99:2044-53. https://doi.org/10.1038/ sj.bjc. 6604786

24. Suchanek KM, May FJ, Robinson JA, Lee WJ, Holman NA, Monteith GR, Roberts-Thomson SJ. Peroxisome proliferator-activated receptor alpha in the human breast cancer cell lines MCF-7 and MDA-MB-231. Mol Carcinog. 2002; 34:165-71. https://doi.org/10.1002/mc.10061

25. Abu Aboud O, Wettersten HI, Weiss RH. Inhibition of PPAR $\alpha$ induces cell cycle arrest and apoptosis, and synergizes with glycolysis inhibition in kidney cancer cells. PLoS One. 2013; 8:e71115. https://doi.org/10.1371/journal. pone.0071115

26. Peters JM, Cattley RC, Gonzalez FJ. Role of PPAR alpha in the mechanism of action of the nongenotoxic carcinogen and peroxisome proliferator Wy-14,643. Carcinogenesis. 1997; 18:2029-33. https://doi.org/10.1093/ carcin/18.11.2029

27. Xu HE, Stanley TB, Montana VG, Lambert MH, Shearer BG, Cobb JE, McKee DD, Galardi CM, Plunket KD, Nolte RT, Parks DJ, Moore JT, Kliewer SA, et al. Structural basis for antagonist-mediated recruitment of nuclear corepressors by PPARalpha. Nature. 2002; 415:813-17. https://doi.org/10.1038/415813a

28. Cimini A, Cristiano L, Benedetti E, D'Angelo B, Cerù MP. PPARs expression in adult mouse neural stem cells: modulation of PPARs during astroglial di $\square$ erentiaton of NSC. PPAR Res. 2007; 2007:48242. https://doi. org/10.1155/2007/48242

29. Tirinato L, Liberale C, Di Franco S, Candeloro P, Benfante A, La Rocca R, Potze L, Marotta R, Ruffilli R, 
Rajamanickam VP, Malerba M, De Angelis F, Falqui A, et al. Lipid droplets: a new player in colorectal cancer stem cells unveiled by spectroscopic imaging. Stem Cells. 2015; 33:35-44. https://doi.org/10.1002/stem.1837

30. Benedetti E, Galzio R, Laurenti G, D’Angelo B, Melchiorre E, Cifone MG, Fanelli F, Muzi P, Coletti G, Alecci M, Sotgiu A, Cerù MP, Cimini A. Lipid metabolism impairment in human gliomas: expression of peroxisomal proteins in human gliomas at different grades of malignancy. Int J Immunopathol Pharmacol. 2010; 23:23546. https://doi.org/10.1177/039463201002300121

31. Laurenti G, Benedetti E, D'Angelo B, Cristiano L, Cinque $\mathrm{B}$, Rahysi S, Alecci M, Cerù MP, Cifone MG, Galzio R, Giordano A, Cimini A. Hypoxia induces peroxisome proliferator-activated receptor $\alpha(\operatorname{PPAR} \alpha)$ and lipid metabolism peroxisomal enzymes in human glioblastoma cells. J Cell Biochem. 2011; 112:3891-901. https://doi. org/10.1002/jcb.23323

32. Dalen KT, Schoonjans K, Ulven SM, Weedon-Fekjaer MS, Bentzen TG, Koutnikova H, Auwerx J, Nebb HI. Adipose tissue expression of the lipid droplet-associating proteins S3-12 and perilipin is controlled by peroxisome proliferator-activated receptor- $\gamma$. Diabetes. 2004; 53:124352. https://doi.org/10.2337/diabetes.53.5.1243

33. Morihiro Y, Yasumoto Y, Vaidyan LK, Sadahiro H, Uchida T, Inamura A, Sharifi K, Ideguchi M, Nomura S, Tokuda N, Kashiwabara S, Ishii A, Ikeda E, et al. Fatty acid binding protein 7 as a marker of glioma stem cells. Pathol Int. 2013; 63:546-53. https://doi.org/10.1111/pin.12109

34. Hostetler HA, McIntosh AL, Atshaves BP, Storey SM, Payne HR, Kier AB, Schroeder F. L-FABP directly interacts with PPARalpha in cultured primary hepatocytes. J Lipid Res. 2009; 50:1663-75. https://doi.org/10.1194/jlr. M900058-JLR200

35. Flavahan WA, Wu Q, Hitomi M, Rahim N, Kim Y, Sloan AE, Weil RJ, Nakano I, Sarkaria JN, Stringer BW, Day BW, Li M, Lathia JD, et al. Brain tumor initiating cells adapt to restricted nutrition through preferential glucose uptake. Nat Neurosci. 2013; 16:1373-82. https://doi. org/10.1038/nn.3510

36. Rakhshandehroo M, Knoch B, Müller M, Kersten S. Peroxisome proliferator-activated receptor alpha target genes. PPAR Res. 2010; 2010:1-20. https://doi. org/10.1155/2010/612089

37. Singh SK, Hawkins C, Clarke ID, Squire JA, Bayani J, Hide T, Henkelman RM, Cusimano MD, Dirks PB. Identification of human brain tumour initiating cells. Nature. 2004; 432:396-401. https://doi.org/10.1038/nature03128

38. Evans SM, Jenkins KW, Jenkins WT, Dilling T, Judy KD, Schrlau A, Judkins A, Hahn SM, Koch CJ. Imaging and analytical methods as applied to the evaluation of vasculature and hypoxia in human brain tumors. Radiat Res. 2008; 170:677-90. https://doi.org/10.1667/RR1207.1

39. Heddleston JM, Hitomi M, Venere M, Flavahan WA, Yang K, Kim Y, Minhas S, Rich JN, Hjelmeland AB. Glioma stem cell maintenance: the role of the microenvironment. Curr Pharm Des. 2011; 17:2386-401. https://doi. org/10.2174/138161211797249260

40. Feige JN, Gelman L, Michalik L, Desvergne B, Wahli W. From molecular action to physiological outputs: peroxisome proliferator-activated receptors are nuclear receptors at the crossroads of key cellular functions. Prog Lipid Res. 2006; 45:120-59. https://doi.org/10.1016/j.plipres.2005.12.002

41. Heneka MT, Landreth GE. PPARs in the brain. Biochim Biophys Acta. 2007; 1771:1031-45. https://doi. org/10.1016/j.bbalip.2007.04.016

42. Bélanger M, Allaman I, Magistretti PJ. Brain energy metabolism: focus on astrocyte-neuron metabolic cooperation. Cell Metab. 2011; 14:724-38. https://doi. org/10.1016/j.cmet.2011.08.016

43. Brahimi-Horn MC, Bellot G, Pouysségur J. Hypoxia and energetic tumour metabolism. Curr Opin Genet Dev. 2011; 21:67-72. https://doi.org/10.1016/j.gde.2010.10.006

44. Pelletier J, Bellot G, Gounon P, Lacas-Gervais S, Pouysségur J, Mazure NM. Glycogen synthesis is induced in hypoxia by the hypoxia-inducible factor and promotes cancer cell survival. Front Oncol. 2012; 2:18. https:/doi. org/10.3389/fonc.2012.00018

45. Pescador N, Villar D, Cifuentes D, Garcia-Rocha M, OrtizBarahona A, Vazquez S, Ordoñez A, Cuevas Y, SaezMorales D, Garcia-Bermejo ML, Landazuri MO, Guinovart J, del Peso L. Hypoxia promotes glycogen accumulation through hypoxia inducible factor (HIF)-mediated induction of glycogen synthase 1. PLoS One. 2010; 5:e9644. https:// doi.org/10.1371/journal.pone.0009644

46. Favaro E, Bensaad K, Chong MG, Tennant DA, Ferguson DJ, Snell C, Steers G, Turley H, Li JL, Günther UL, Buffa FM, McIntyre A, Harris AL. Glucose utilization via glycogen phosphorylase sustains proliferation and prevents premature senescence in cancer cells. Cell Metab. 2012; 16:751-64. https://doi.org/10.1016/j.cmet.2012.10.017

47. Mimura I, Nangaku M, Kanki Y, Tsutsumi S, Inoue T, Kohro T, Yamamoto S, Fujita T, Shimamura T, Suehiro J, Taguchi A, Kobayashi M, Tanimura K, et al. Dynamic change of chromatin conformation in response to hypoxia enhances the expression of GLUT3 (SLC2A3) by cooperative interaction of hypoxia-inducible factor 1 and KDM3A. Mol Cell Biol. 2012; 32:3018-32. https://doi. org/10.1128/MCB.06643-11

48. Liu Y, Li YM, Tian RF, Liu WP, Fei Z, Long QF, Wang $\mathrm{XA}$, Zhang X. The expression and significance of HIF-1 $\alpha$ and GLUT-3 in glioma. Brain Res. 2009; 1304:149-54. https://doi.org/10.1016/j.brainres.2009.09.083

49. Ilkhanizadeh S, Weiss WA. Starvation favors glioma stem cells. Nat Neurosci. 2013; 16:1359-61. https://doi. org/10.1038/nn.3524

50. Santos MJ, Quintanilla RA, Toro A, Grandy R, Dinamarca MC, Godoy JA, Inestrosa NC. Peroxisomal proliferation protects from beta-amyloid neurodegeneration. J Biol 
Chem. 2005; 280:41057-68. https://doi.org/10.1074/jbc. M505160200

51. Cisternas P, Salazar P, Silva-Álvarez C, Barros LF, Inestrosa NC. Activation of Wnt Signaling in Cortical Neurons Enhances Glucose Utilization through Glycolysis. J Biol Chem. 2016; 291:25950-64. https://doi.org/10.1074/ jbc.M116.735373

52. DeBerardinis RJ, Lum JJ, Hatzivassiliou G, Thompson CB. The biology of cancer: metabolic reprogramming fuels cell growth and proliferation. Cell Metab. 2008; 7:11-20. https://doi.org/10.1016/j.cmet.2007.10.002

53. Mandard S, Stienstra R, Escher P, Tan NS, Kim I, Gonzalez FJ, Wahli W, Desvergne B, Müller M, Kersten S. Glycogen synthase 2 is a novel target gene of peroxisome proliferatoractivated receptors. Cell Mol Life Sci. 2007; 64:1145-57. https://doi.org/10.1007/s00018-007-7006-1

54. Abu-Hamad S, Zaid H, Israelson A, Nahon E, ShoshanBarmatz V. Hexokinase-I protection against apoptotic cell death is mediated via interaction with the voltagedependent anion channel-1: mapping the site of binding. J Biol Chem. 2008; 283:13482-90. https://doi.org/10.1074/ jbc.M708216200

55. Kucharzewska P, Christianson HC, Belting M. Global profiling of metabolic adaptation to hypoxic stress in human glioblastoma cells. PLoS One. 2015; 10:e0116740. https:// doi.org/10.1371/journal.pone.0116740

56. Bensaad K, Favaro E, Lewis CA, Peck B, Lord S, Collins JM, Pinnick KE, Wigfield S, Buffa FM, Li JL, Zhang Q, Wakelam MJ, Karpe F, et al. Fatty acid uptake and lipid storage induced by HIF- $1 \alpha$ contribute to cell growth and survival after hypoxia-reoxygenation. Cell Reports. 2014; 9:349-65. https://doi.org/10.1016/j.celrep.2014.08.056

57. Fink T, Abildtrup L, Fogd K, Abdallah BM, Kassem M, Ebbesen P, Zachar V. Induction of adipocyte-like phenotype in human mesenchymal stem cells by hypoxia. Stem Cells. 2004; 22:1346-55. https://doi.org/10.1634/ stemcells.2004-0038

58. Ta MT, Kapterian TS, Fei W, Du X, Brown AJ, Dawes IW, Yang H. Accumulation of squalene is associated with the clustering of lipid droplets. FEBS J. 2012; 279:4231-44. https://doi.org/10.1111/febs.12015
59. Riganti C, Massaia M. Inhibition of the mevalonate pathway to override chemoresistance and promote the immunogenic demise of cancer cells: killing two birds with one stone. OncoImmunology. 2013; 2:e25770-73. https:// doi.org/10.4161/onci.25770

60. Yao CJ, Lai GM, Chan CF, Cheng AL, Yang YY, Chuang SE. Dramatic synergistic anticancer effect of clinically achievable doses of lovastatin and troglitazone. Int J Cancer. 2006; 118:773-79. https://doi.org/10.1002/ijc.21361

61. Derr RL, Ye X, Islas MU, Desideri S, Saudek CD, Grossman SA. Association between hyperglycemia and survival in patients with newly diagnosed glioblastoma. J Clin Oncol. 2009; 27:1082-86. https://doi.org/10.1200/ JCO.2008.19.1098

62. Duan W, Shen X, Lei J, Xu Q, Yu Y, Li R, Wu E, Ma Q. Hyperglycemia, a neglected factor during cancer progression. BioMed Res Int. 2014; 2014:461917. https:// doi.org/10.1155/2014/461917

63. Ryu TY, Park J, Scherer PE. Hyperglycemia as a risk factor for cancer progression. Diabetes Metab J. 2014; 38:330-36. https://doi.org/10.4093/dmj.2014.38.5.330

64. Osawa T, Shibuya M. Targeting cancer cells resistant to hypoxia and nutrient starvation to improve anti-angiogeneic therapy. Cell Cycle. 2013; 12:2519-20. https://doi. org/10.4161/cc.25729

65. Boroughs LK, DeBerardinis RJ. Metabolic pathways promoting cancer cell survival and growth. Nat Cell Biol. 2015; 17:351-59. https://doi.org/10.1038/ncb3124

66. O’Neil RG, Wu L, Mullani N. Uptake of a fluorescent deoxyglucose analog (2-NBDG) in tumor cells. Mol Imaging Biol. 2005; 7:388-92. https://doi.org/10.1007/ s11307-005-0011-6

67. Zou C, Wang Y, Shen Z. 2-NBDG as a fluorescent indicator for direct glucose uptake measurement. J Biochem Biophys Methods. 2005; 64:207-15. https://doi.org/10.1016/j. jbbm.2005.08.001

68. Livak KJ, Schmittgen TD. Analysis of relative gene expression data using real-time quantitative PCR and the 2(-Delta Delta C(T)) Method. Methods. 2001; 25:402-08. https://doi.org/10.1006/meth.2001.1262 